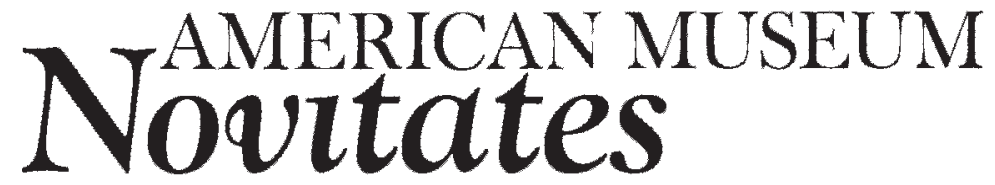

PUBLISHED BY THE AMERICAN MUSEUM OF NATURAL HISTORY CENTRAL PARK WEST AT 79TH STREET, NEW YORK, NY 10024 Number 3559, 27 pp., 22 figures, 2 tables

March 8, 2007

\title{
Element Homology and the Evolution of Dental Formulae in Megachiropteran Bats (Mammalia: Chiroptera: Pteropodidae)
}

\author{
NORBERTO P. GIANNINI ${ }^{1}$ AND NANCY B. SIMMONS ${ }^{1}$
}

\begin{abstract}
Variation in dental formulae observed in megachiropteran bats poses element homology problems. Identity of individual teeth has been controversial, with authors differing in their assessment of individual tooth homology, particularly with respect to incisors and premolars, in several taxa. Also, newly described taxa exhibit dental formulae whose implications for tooth homology have been little discussed. We compared crown morphology, tooth replacement, and dental anomalies in representatives of all megachiropteran genera. Our observations confirm the generalized megachiropteran dental formula (34 teeth represented by I1, I2, C, P1, P3, P4, M1, M2, $\mathrm{i} 1, \mathrm{i} 2, \mathrm{c}, \mathrm{p} 1, \mathrm{p} 3, \mathrm{p} 4, \mathrm{~m} 1, \mathrm{~m} 2$, and $\mathrm{m} 3$ ) and establishes the homology of each tooth in most megachiropteran taxa in which reduction in tooth number has taken place. Some of our conclusions confirm presumed homologies postulated by previous authors, but in other cases new homology assignments are proposed. Uncorroborated assignments are reduced to just two taxa, Harpyionycteris and Nyctimeninae, both of which remain problematic with respect to homologies of the incisor dentition. Mapping tooth presence/absence on previously published phylogenetic trees reveals modest levels of ambiguity and homoplasy in patterns of tooth reduction in Pteropodidae, and indicates that reversals involving the reappearance of an ancestrally lost tooth may have taken place. Our results are consistent with dental field theory, which explains both reversals and anomalies as a regulatory variation that does not affect element homology because the latter is supported by structural genes.
\end{abstract}

\footnotetext{
${ }^{1}$ Division of Vertebrate Zoology (Mammalogy), American Museum of Natural History (N.P.G.: norberto@amnh.org; N.B.S.: simmons@amnh.org).
} 


\section{INTRODUCTION}

The primitive eutherian dentition is presumed to comprise 50 teeth representing four distinct classes, which can be distinguished based on position, morphology, and replacement: five upper and four lower incisors, one upper and lower canine, five upper and lower premolars, and three upper and lower molars, abbreviated I5/4, C1/1, P5/5, M3/3 (KielanJaworowska et al., 2004). Extant eutherians bear a maximum of 44 teeth (I3/3, C1/1, P4/4, $\mathrm{M} 3 / 3)$. This complement is further reduced in all bats, which have a maximum of 38 teeth (I2/3, C1/1, P3/3, M3/3; Miller, 1907; Slaughter, 1970). This dental formula appears in some or all members of four microchiropteran families (Natalidae, Myzopodidae, Thyropteridae, and Vespertilionidae; Koopman, 1994). At the other end of the spectrum, the tooth count is reduced to just 20 teeth in Desmodus rotundus (Phyllostomidae; I1/2, C1/ 1, P1/2, M1/1; Miller, 1907).

Megachiropterans (Pteropodidae) have dentitions that comprise between 24 and 34 teeth. The complete megachiropteran formula (i.e., containing the greatest number of teeth) is I $2 /$ 2, C1/1, P3/3, M2/3 (Miller, 1907; Andersen, 1912; Koopman, 1994). This formula is seen in a dozen genera including Pteropus. The homology of incisors and premolars in the megachiropteran dentition has traditionally been a source of controversy. To Miller (1907), the upper incisors present in megabats are homologous to the second and third of the primitive formula of extant eutherians, while the lower incisors are homologous with the first and second; the premolar missing in all bats is the first of the eutherian formula. According to Miller (1907), the complete megabat formula should thus be written I2 I3 C P2 P3 P4 M1 M2 for the upper dentition and i1 i2 C p2 p3 p4 m1 m2 m3 for the lower dentition. In contrast, Andersen (1908, 1912) identified the upper and lower incisors of megabats as homologous to the first and second incisors of most eutherians, and he followed Thomas (1908) in recognizing the missing chiropteran premolar as the second of the basic formula of extant eutherians. Under this hypothesis, the complete megabat formula could be written I1 I2 C P1 P3 P4 M1 M2 for the upper dentition and i1 i2 C p1 p3 p4 m1 $\mathrm{m} 2 \mathrm{~m} 3$ for the lower dentition. Subsequent authors, from the beginning of the 20th century to the present, have either followed Miller (1907; e.g., Bates and Harrison, 1997) or Andersen (1912; e.g., Slaughter, 1970). The underlying problem in this controversy is the uncertain element homology of the megachiropteran dentition.

Nine genera (Aethalops Thomas, 1923; Alionycteris Kock, 1969a; Aproteles Menzies, 1977; Haplonycteris Lawrence, 1939; Latidens Thonglongya, 1972; Mirimiri Helgen, 2005; Neopteryx Hayman, 1946; Otopteropus Kock, 1969b; and Paranyctimene Tate, 1942) and many species (e.g., Myonycteris relicta Bergmans, 1980) have been described since Andersen's (1912) Catalogue was published. Although no essentially new tooth morphologies have been discovered, many of the more recently described taxa include forms with dental formulae not present in the megachiropteran samples available to Miller and Andersen. This additional variation, as well as some anomalies and assumptions of the dental formulae, remain unaccounted for in terms of their implications for homology statements. In this contribution, we review the available evidence on tooth homology in Megachiroptera and present new data from specimens and taxa not previously discussed in this context. We base our homology statements on comparative anatomy of tooth structure, relationships of the deciduous dentition to the permanent dentition, and dental anomalies. After an analysis of representatives of all pteropodid genera, we provide new evidence to support hypotheses of element homology in the megachiropteran dental formula.

\section{METHODS}

The goal of our study was to establish primary homology of each tooth in the megachiropteran dentition. To that end, we examined skulls of standard museum specimens from the following collections: American Museum of Natural History (AMNH), Natural History Museum, London (BMNH), Field Museum of Natural History, Chicago (FMNH), Harrison Zoological Museum, Sevenoaks, UK (HZM), and Koninklijk 
Museum voor Midden-Africa/Musée Royal de l'Afrique Centrale, Tervuren, Belgium (KMMA/MRAC). We surveyed large numbers of specimens of megabat species available in these collections for evidence that could aid in establishing the homology of each element of the dentition: features of crown structure of unworn teeth, patterns of tooth replacement, morphology of deciduous teeth, and dental anomalies. To support our homology statements, we refer throughout the text to specimens used in our comparisons; these discussions do not reflect the much larger number of specimens we surveyed in an effort to locate juvenile specimens, young adults, and individuals with anomalous dentitions.

We compared crown morphology in species with reduced numbers of teeth and searched for possible homologs in closely related species with more complete dental formulae. We relied on the phylogenetic hypotheses of megachiropteran relationships proposed by Giannini and Simmons (2005) as a reference, and used other classifications (Bergmans, 1997; Koopman, 1994) to identify close relatives in those genera not included in Giannini and Simmons (2005). For instance, homology of the single incisor found in some species was assessed through comparisons with the incisors of closely related species that bear the complete incisor set (two). We did not make a priori assumptions that the same teeth must be lacking in all species with reduced dental formulae. With respect to tooth replacement, we took advantage of the fact that in all megachiropterans in which deciduous tooth replacement has been observed (see Andersen, 1912; Giannini et al., 2006), the topography of such replacement is apparently fixed within species (e.g., Pteropus lylei; Giannini et al., 2006). That is, a close correspondence exists between the insertion site of the deciduous tooth and the emergence site of its permanent replacement, which sometimes share the same alveolus; thus, tooth replacement appears as a reliable indicator of homology of the permanent set. An example in megachiropterans is represented by the proposed homology of the upper incisors in Dobsonia (Andersen, 1912; see Incisors below).

Dental anomalies of some kinds (e.g., departures from species-specific dental formu- lae) have been considered to be atavistic (e.g., Handley, 1959; Phillips, 1971; Miles and Grigson, 1990). These anomalies can be interpreted as reversals to a character state atypical of the species but present in related taxa, and may therefore be indicative of homology. Of those anomalies, supernumerary teeth are the most relevant, because in megachiropterans the trend appears to be to reduce the number of normal permanent teeth in some lineages (Andersen, 1912). The presence of anomalous additional teeth thus may help determine the identity of teeth lost during evolution. We considered as atavistic any additional element that occurred in a position corresponding to a tooth typically present in other forms and that could be morphologically linked to it. We reexamined most of Andersen's specimens (some are no longer available in collections) and report additional specimens with such anomalies that shed light on tooth homology.

Some dental anomalies cannot be interpreted in terms of homology because neither the location of the element nor its morphology can be related to any tooth in forms with more complete dentition and/or undisputed homology. In this category fall the 16 megachiropteran specimens from the $\mathrm{BMNH}$ and other collections reported by Andersen (1912) as having "accidental outgrowths" in the dentition. For instance, an extra, peglike tooth is present between normal P3 and P4 on the right side of Epomophorus gambianus BMNH 99.6.15.2 (fig. 1). This type of variation is widespread in mammals (Miles and Grigson, 1990) and is not considered here because it appears to have no bearing on dental homologies.

\section{RESULTS AND DISCUSSION}

\section{INCISORS}

With the exception of Aproteles bulmerae, which completely lacks incisor teeth (Menzies, 1977), all megachiropterans have one or two upper and lower incisors, and the precise homology of each tooth has been debated. Considering bats in general, Thomas (1908) argued that the chiropteran incisors are I1 and I2, contra Miller (1907) who proposed that they are homologous with I 2 and I3 of other 


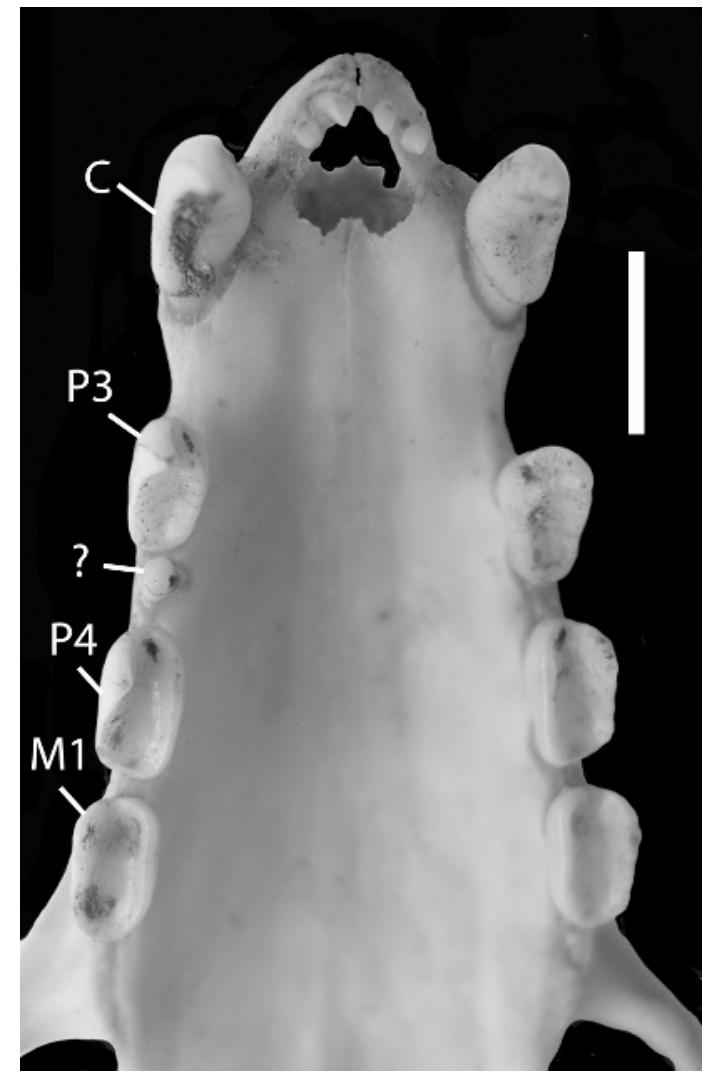

Fig. 1. Epomophorus gambianus BMNH 99.6.15.2, view of the palate. An extra, peglike tooth (?) is present on the right side between typical posterior premolars, which are undisputed P3 and P4 of the dental formula of extant eutherians. Abbreviations: C upper canine, M1 first upper molar, P3 third upper premolar, P4 fourth upper premolar. Scale $=5 \mathrm{~mm}$.

mammals. Miller's (1907) view was mainly based on vespertilionids (microbats he presumed primitive on the basis of tooth count and other characters), in which the first upper incisor is smaller than the second and no diastema exists between the second incisor and the upper canine. That morphology suggests a rostral reduction of incisors (loss of I1).

In turn, Thomas's (1908) hypothesis that the two upper incisors of bats represent I1 and I2 received support from Andersen's (1908) analysis, which included megachiropterans. Frequently in pteropodids (presumed primitive by Andersen, 1908), the four upper incisors (two on the right and two on the left) lie close together with no medial diastema, whereas the lateral incisors are separated from the canine by a diastema (fig. 1). This diastema is often magnified by a caudoventral reduction of the premaxilla that forms a deep notch in front of the canine (see character 85 in Giannini and Simmons, 2005). Andersen (1908) also noted that in most bats (with vespertilionids being more an exception than the rule), the size relationship is such that the first incisor is significantly larger than the second. Allen (1916) reported the bilateral presence of a morphologically distinct I3 in addition to the normal I1 and $\mathrm{I} 2$ in a vespertilionid (Plecotus townsendi), supporting the idea that the teeth normally present are indeed I1 and I2. In addition, Andersen (1912: xxxiii) reported the presence of a "reduplicated" I2 in Cynopterus sphinx (BMNH 6.11.6.42; fig. 2). Miles and Grigson (1990) used the term "connate tooth" to describe a tooth that has two separate roots and two partially fused crowns. Connate teeth are rare in mammals, and have been interpreted as originating from fusion of two independent elements (Miles and Grigson, 1990). The "reduplicated I2" Andersen (1912) identified in BMNH 6.11.6.42 has this morphology, which suggests that it is probably an atavistic I3 that interfered with the development of a normal I2.

We concur with Andersen (1908) and Thomas (1908) in concluding that the chiropteran incisors represent I1 and I2 whenever two upper incisors are present, with the corollary that either I1 or I 2 is absent when just one incisor is present in a species. In the lower dentition, there has always been agreement that $\mathrm{i} 3$ is the tooth that has been lost when only two incisors remain in the dentition (Miller, 1907; Andersen, 1908; Thomas, 1908). Specifically Andersen (1908: 206) stated that in most bat genera with three lower incisors these elements were "subequal in size", with some exceptions (e.g., Rhogeessa [Vespertilionidae] and Mormopterus [Molossidae]) in which the third incisor was the one "noticeably, or even considerably, reduced"; so "From this it appears safe to assume that in bats which have only two pairs of lower incisors, the missing pair is i3." Additional reductions affecting either i1 or i2 must be evaluated on a case-by-case basis (see below). 


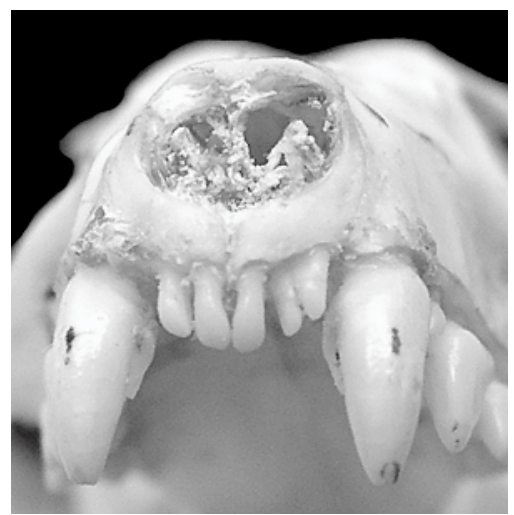

Fig. 2. Cynopterus sphinx BMNH 6.11.6.42, presence of a connate incisor formed by the fusion of the crowns of a normal incisor (I2) and a probably atavistic I3.

When just one incisor is present, the precise identity of the single element must be determined (I1 versus I2 and/or i1 versus i2). In Boneia and Notopteris, the relatively caudal position of the single upper incisor in the upper dental arch clearly suggests that the missing incisor is I1, especially when compared with related species with two upper incisors (Eonycteris major and Melonycteris melanops, respectively; figs. 3 and 4). The same holds for the lower incisor in Notopteris and Melonycteris woodfordi (il lost; see comparison with Melonycteris melanops in fig. 5). However, loss of I1 seems to be an incomplete process in Boneia: out 10 specimens examined by Bergmans and Rozendaal (1988), traces of I1 alveoli were present in 1 individual, and I1 was present unilaterally or bilaterally in another 2 specimens.

The relative position of single incisors relative to diastemata is a feature not available in megachiropterans in which the lower intercanine space is somewhat restricted by the medial displacement of the canines (e.g., in Harpyionycterinae sensu Giannini et al., 2006, Styloctenium, Nyctimeninae, and Cynopterinae); therefore the homology of the single element is much less obvious in these forms. By comparison with its close relatives (the pteropodines Acerodon, Neopteryx, and Pteropus) Andersen (1912) concluded that Styloctenium preserves i2, a relatively large

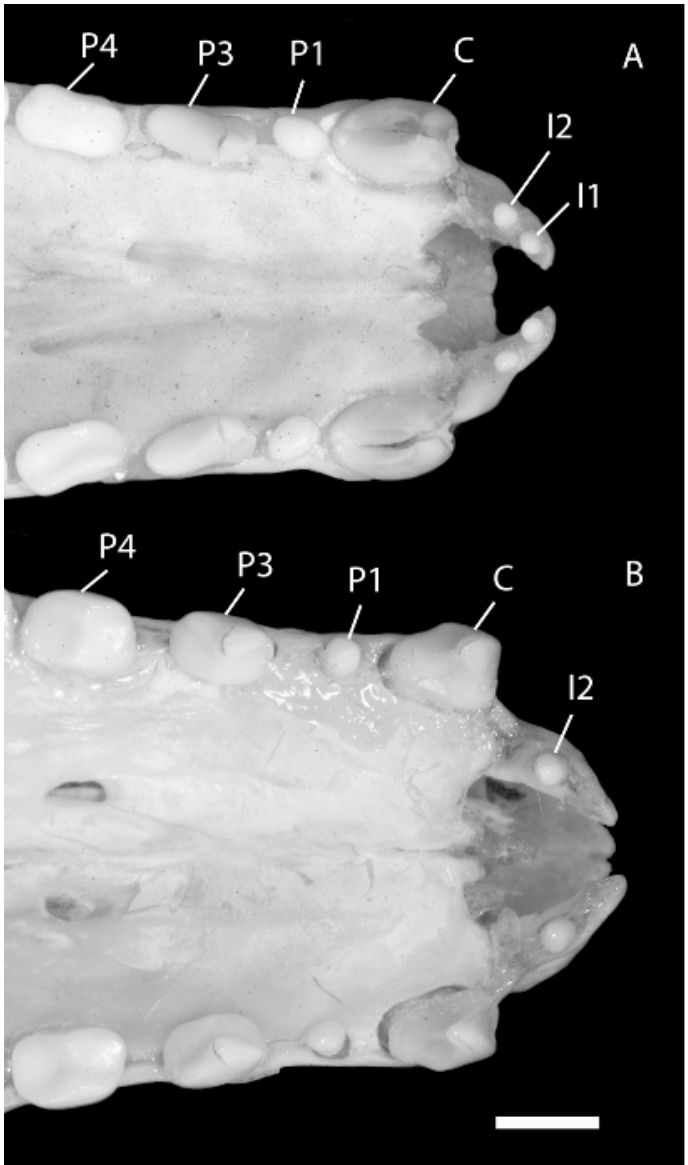

Fig. 3. Eonycteris major AMNH 130319 (A) and Rousettus (Boneia) bidens (B), ventral view of the anterior palate and dentition showing the hypothesized loss of the first upper incisor in $R$. bidens (see text). Abbreviations: $\mathrm{C}$ upper canine, I1 first upper incisor, I2 second upper incisor, P1 first upper premolar, $\mathrm{P} 3$ third upper premolar, $\mathrm{P} 4$ fourth upper premolar. Scale $=2 \mathrm{~mm}$.

tooth, without loss of crown structure; in the three genera used as reference, i1 has half or less of the bulk of i2 and is a rather featureless peg or spicule. We concur with this assessment on the basis of our examination of Styloctenium wallacei AMNH 196449, 222980, and 222981.

In other forms, Andersen (1912) tackled the I1 versus $\mathrm{I} 2$ problem by examining the correspondence between deciduous and permanent teeth. His most relevant example is in Dobsonia. This genus has two upper and two 


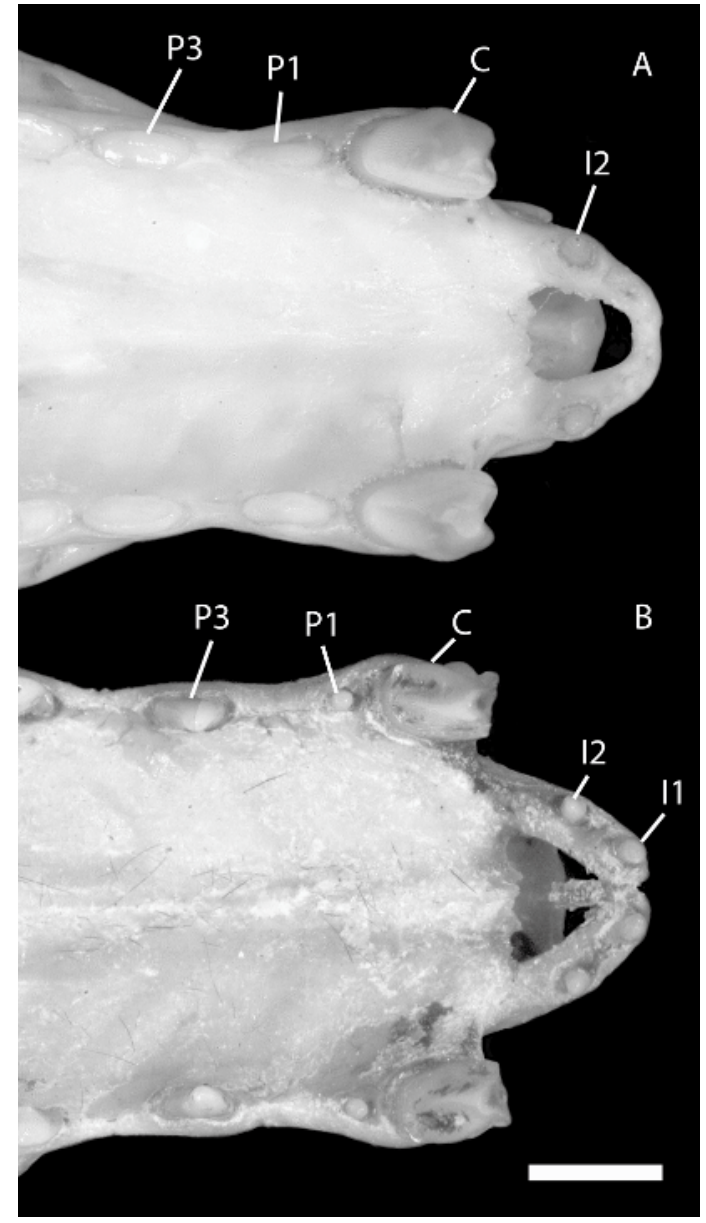

Fig. 4. Notopteris macdonaldi AMNH 119455 (A) and Melonycteris melanops AMNH 194333 (B), ventral view of the anterior palate and dentition showing the hypothesized loss of the first upper incisor in $N$. macdonaldi (see text). Abbreviations: C upper canine, I1 first upper incisor, I2 second upper incisor, P1 first upper premolar, P3 third upper premolar. Scale $=2 \mathrm{~mm}$.

lower deciduous incisors, but the permanent dentition exhibits only one upper and one lower incisor. Based on D. praedatrix (and always assuming that the two upper incisors in bats are I1 and I2), Andersen (1912) showed that the upper permanent incisor emerges as a replacement of $\mathrm{dI} 2$. Therefore, the missing permanent tooth must be I1. We confirmed the same pattern of replacement in Dobsonia magna (AMNH 109854, 157337), D. pannietensis (AMNH 159113, 159142, 159150) and

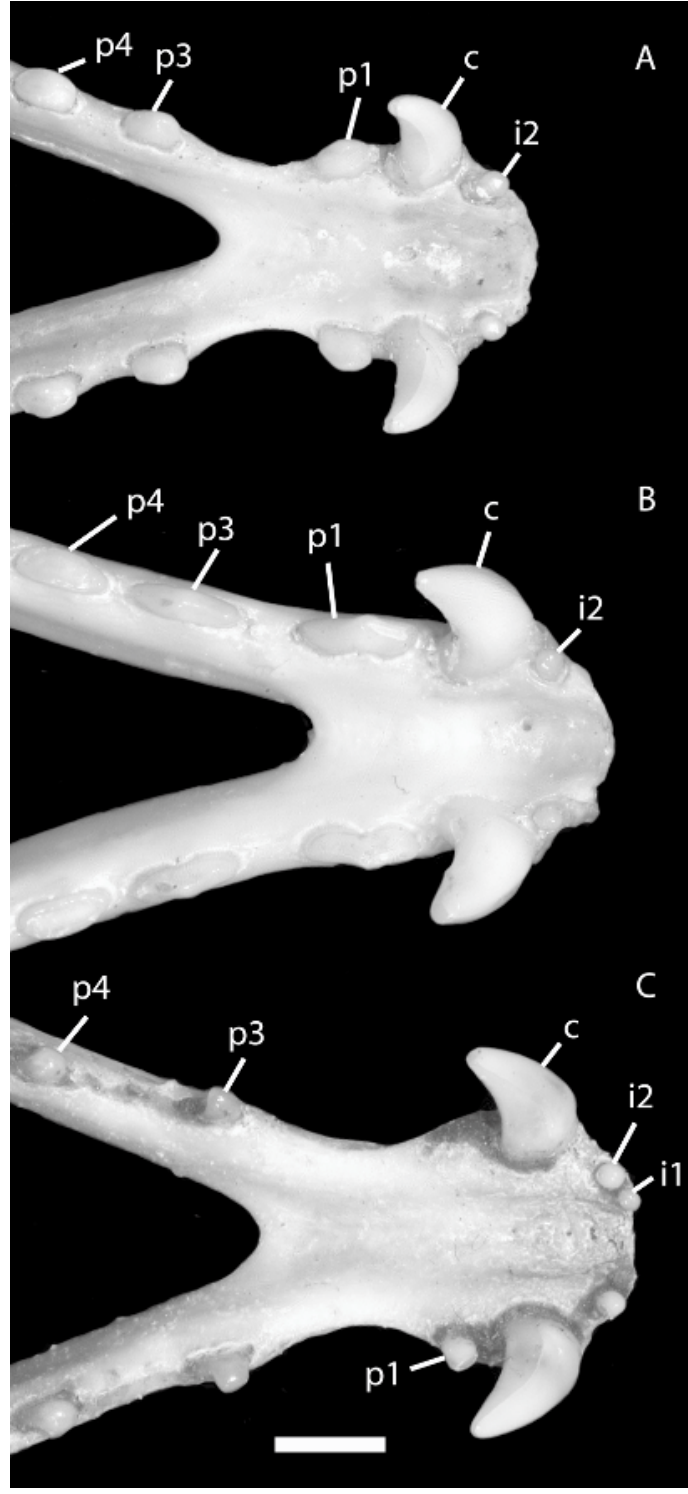

Fig. 5. Melonycteris (Nesonycteris) woodfordi AMNH 99950 (A), Notopteris macdonaldi AMNH 119455 (B), and Melonycteris melanops AMNH 194333 (C), occlusal view of the anterior mandible showing the hypothesized loss of the first lower incisor in $M$. woodfordi and $N$. macdonaldi (see text). Note that in M. melanops the right first lower incisor is lost and the left il is smaller than i2. Abbreviations: c lower canine, i1 first lower incisor, i2 second lower incisor, p1 first lower premolar, p3 third lower premolar, p4 fourth lower premolar. Scale $=2 \mathrm{~mm}$. 
D. peronii (AMNH 107632). In those specimens, the alveolus of dI1 is distinctly isolated, whereas dI2 shares the alveolus with an emerging permanent incisor, which therefore must be I2 (fig. 6). That is, the identity of the missing incisor as I1 seems reasonably established given that a consistent pattern has been found in members of three of the four Dobsonia species groups (i.e., moluccensis, peronii, and viridis; evidence wanting in the minor species group).

In the lower dentition, Andersen (1912) similarly recognized il as the missing incisor tooth. However the evidence he presented is less compelling and is limited to a possible correlation between degree of reduction in deciduous and permanent teeth and the size relationship between i1 and i2 in presumably related genera, Pteropus and Rousettus. On this basis, the permanent tooth should be i2, because in Dobsonia dil is smaller than di2 and because il is smaller than i2 in Pteropus and Rousettus. Although the deciduous-permanent size correlation has been observed in other genera (e.g., Pteropus; see fig. 42 in Giannini et al., 2006), this is hardly compelling evidence in isolation, in part because a close relationship Andersen (1912) assumed between Dobsonia and either Pteropus or Rousettus has not been supported in recent phylogenetic studies (Giannini and Simmons, 2003, 2005). Fortunately, examination of deciduous-permanent topographical correspondence allowed us to confirm the identity of the single lower incisor, at least in the large species D. magna. In AMNH 108486 and 109854, the alveolus of dil is separated from the alveolus of di2 by a distinct bony lamina, and di2 shares the alveolus with the emerging permanent incisor (fig. 7). Therefore, we conclude that in Dobsonia, the single lower incisor is i2.

The two genera most closely related to Dobsonia are Aproteles and Harpyionycteris (Giannini et al., 2006). Aproteles lacks incisors in the permanent dentition, but it is not clear if there is a corresponding reduction in the deciduous set (see Nyctimene and Paranyctimene below). In the case of Harpyionycteris (a genus with remarkable tooth structures), Andersen (1912) relied on his hypothesis of a close association of Harpyionycteris (another genus with one upper

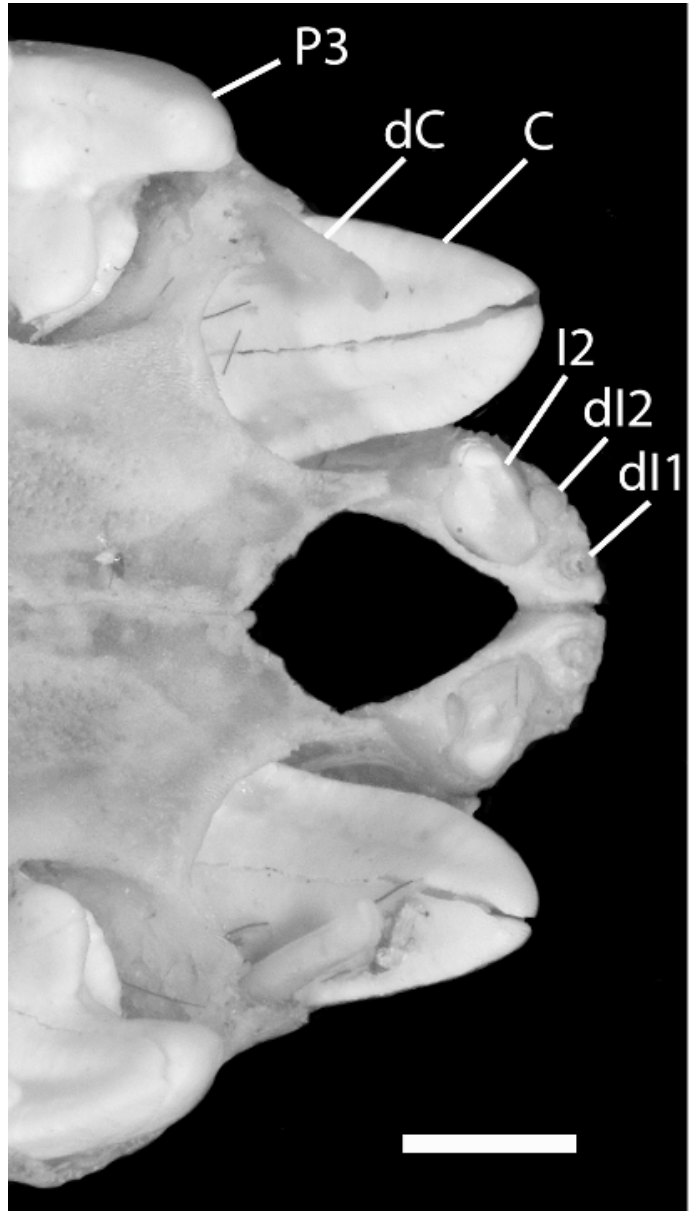

Fig. 6. Dobsonia pannietensis AMNH 159142, oblique ventrocaudal view of the anterior palate showing the pattern of replacement of upper incisors. Abbreviations: $\mathrm{C}$ upper canine, $\mathrm{dC}$ deciduous upper canine, dI1 deciduous first upper incisor, dI2 deciduous second upper incisor, P3 third upper premolar. Scale $=2 \mathrm{~mm}$.

and one lower incisors) with Dobsonia, concluding that the missing teeth in the former should also be I1 and il. We were unable to test that conclusion based on examination of specimens, as no sufficiently young individuals were available to us. The small, bilobed lower incisors of Harpyionycteris, which are often shed early in life, are similar in morphology to the single lower incisor in Dobsonia, but the large, highly distinct upper incisor escapes direct morphological comparison with any megachiropteran incisor. Accordingly, the 


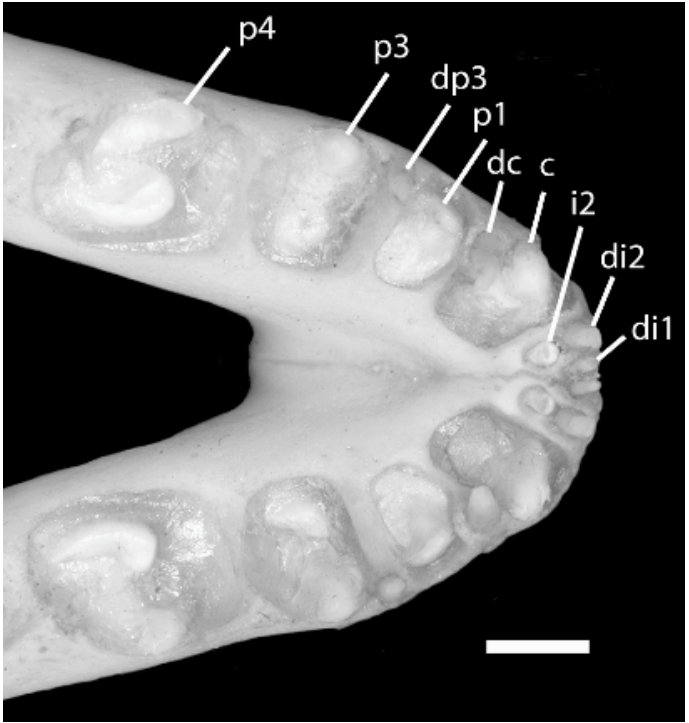

Fig. 7. Dobsonia magna AMNH 108486, occlusal view of the anterior mandible showing pattern of replacement of lower incisors. Abbreviations: c lower canine, dc deciduous lower canine, dil deciduous first lower incisor, di2 deciduous second lower incisor, dp3 deciduous third lower premolar, i2 second lower incisor, p1 first lower premolar, p3 third lower premolar, p4 fourth lower premolar. Scale $=2 \mathrm{~mm}$.

homologies of the permanent incisors in Harpyionycteris thus remain uncertain because the deciduous dentition is unknown and incisor morphologies (of the upper tooth at least) are too different to be meaningfully compared morphologically. However, based on molecular data, Giannini et al. (2006) confirmed that Harpyionycteris is a close relative of Dobsonia, which at least validates the attempt to assimilate the condition seen in the former to that of the latter for provisional homology determination. With some trepidation, we accept as the best present working hypothesis Andersen's (1912) conclusion that the incisor teeth in Harpyionycteris represent I 2 and $\mathrm{i} 2$.

In 1912, all known cynopterines had two upper incisors, whereas four genera (Balionycteris, Megaerops, Penthetor, and Ptenochirus) possessed only a single lower incisor that was assumed by Andersen (1912) to be i2. Another taxon described soon after, Aethalops alecto Thomas, 1923, was similar in that it presented the same incisor count (two upper and one lower incisor). Interestingly, a series of newly discovered cynopterine genera described in subsequent decades (i.e., the monotypic Haplonycteris Lawrence, 1939, Latidens Thonglongya, 1972, Otopteropus Kock, 1969a, and Alionycteris Kock, 1969b) later posed the problem of the presence of only a single upper incisor. Table 1 summarizes our homology assignments for cynopterine genera with reduced incisor dentitions. Our assessments are in each case based on comparisons of the single-toothed species with closely related taxa having morphologically similar dentitions that conserve the two lower/upper incisors (unfortunately, juvenile specimens preserving deciduous dentitions are not presently available for any of these taxa).

Dealing with lower incisors first, we identified several different conditions in cynopterines. One group of genera (Aethalops, Alionycteris, Haplonycteris, and Otopteropus) apparently retained the first lower incisor and lost the second. That conclusion derives from comparing the dentition of those genera with the close relative Chironax, and contrasts with Kock's (1969a, 1969b) homology assessment for Alionycteris and Otopteropus (he suggested that il was lost in these taxa). The il of Chironax (fig. 8A) is smaller and has a less marked caudal cingulum than i2; i1 is also a slightly bilobed, asymmetrical tooth, and the main cusp of the left and right il converge medially. The relative size and crown morphology of il in Chironax closely resembles that of the single tooth in Alionycteris and Otopteropus (fig. 8D). This is also true in Aethalops and Haplonycteris, in which the bilobed condition of the incisor is additionally more strongly marked (fig. 8B,C). Also by comparison with Chironax, the single lower incisor of the monotypic Balionycteris does not conform to the morphology of il but with that of i2 (fig. 8, cf. A and E). In Balionycteris, the single incisor is relatively large, the asymmetry of the tooth is not marked, and the caudal cingulum is large-features that correspond with those of the $\mathrm{i} 2$ in Chironax (see also Cynopterus below).

Megaerops and Ptenochirus are close relatives of Cynopterus (see Giannini and Simmons, 2005) and the dentition is, in 
TABLE 1

Summary of Proposed Homology of Single Incisors in Genera of Cynopterinae Bats Based on Comparisons with Related Taxa with Two Lower Incisors (Left Columns) or Two Upper Incisors (Right Columns) ${ }^{\mathrm{a}}$

\begin{tabular}{|c|c|c|c|c|c|c|}
\hline \multirow[b]{2}{*}{ Genus } & \multicolumn{3}{|c|}{ Lower incisors } & \multicolumn{3}{|c|}{ Upper incisors } \\
\hline & il & i2 & By comparison with & I1 & $\mathrm{I} 2$ & By comparison with \\
\hline Haplonycteris & 1 & 0 & Chironax & 0 & 1 & Aethalops alecto \\
\hline Otopteropus & 1 & 0 & Chironax & 0 & 1 & Aethalops alecto \\
\hline Alionycteris & 1 & 0 & Chironax & 0 & 1 & Aethalops alecto \\
\hline Aethalops & 1 & 0 & Chironax & 1 & 1 & $\mathrm{n} / \mathrm{a}$ \\
\hline Balionycteris & 0 & 1 & Chironax & 1 & 1 & $\mathrm{n} / \mathrm{a}$ \\
\hline Megaerops & 0 & 1 & Cynopterus & 1 & 1 & $\mathrm{n} / \mathrm{a}$ \\
\hline Ptenochirus & 0 & 1 & Cynopterus & 1 & 1 & $\mathrm{n} / \mathrm{a}$ \\
\hline Penthetor & 0 & 1 & Thoopterus/Latidens & 1 & 1 & $\mathrm{n} / \mathrm{a}$ \\
\hline Latidens & 0 & 1 & Thoopterus & 1 & 0 & Thoopterus/Penthetor \\
\hline
\end{tabular}

"Tooth presence $=$ "1" and tooth absence $=$ "0". For example, the first row indicates that Haplonycteris is hypothesized to have i1 present and i2 absent by comparison with Chironax, and I1 absent and I2 present by comparison with Aethalops alecto. Abbreviations: i1, first lower incisor; i2, second lower incisor; I1, first upper incisor; I2, second upper incisor; n/a, comparison not applicable (i.e., not necessary because the incisor set is complete in the genus under consideration).

general, similar in the three genera. By comparison with Cynopterus, the single lower incisor of Ptenochirus corresponds to the i2 of Cynopterus, based both on the absolute size of the element as well as on the development of the caudal cingulum (fig. 9). In addition, the single incisor in Ptenochirus (e.g., P. jagori AMNH 203262) is comparatively very large and symmetrically bilobed (fig. 10C). The situation is less clear in Megaerops. Andersen (1912) indicated that i1 was lacking and i2 was present and unmodified in this taxon, but in most specimens the single incisor present is reduced to an almost featureless spicule. However, the caudal cingulum of the single incisor in Megaerops (e.g., $M$. niphanae AMNH 238183; fig. 9C) is rounded as in the i2 of Cynopterus (as opposed to the pointed caudal cingulum of the reduced il in this genus; fig. 9, cf. A and C). Also, the roots of left and right single incisors in most specimens of Megaerops are slightly separated (fig. 10B), suggesting a missing inner rather than outer incisor. This evidence is not strong, but it suggests to us that Andersen's (1912) hypothesis that il has been lost in Megaerops is tenable.

By comparison with Thoopterus, the slightly bowed lower incisor of Penthetor and Latidens also appears to be i2 (fig. 11). However, the case of Penthetor is not as clear as in Latidens, because in the former the single incisor is small and rather featureless in most individuals, whereas in the latter the single incisor is of similar size and shape as the $\mathrm{i} 2$ of Thoopterus (figs. 11, 12). Some individuals of Thoopterus have apparently lost one incisor during their lifetime: the type specimen (BMNH 62.10.21.6) has its left i2 missing, whereas AMNH 222771 has lost its left il. Given this inconsistency, naturally shed teeth cannot afford evidence to clarify the case of Penthetor. However, in some $P$. lucasi the single incisor is either displaced toward the canine (e.g., AMNH 106820, 106826, 106930; fig. $11 \mathrm{C}$ ) or the tooth resembles the incisor of some Latidens (e.g., compare P. lucasi AMNH 106826 and 106832 with L. salimalii HZM 3.26435). Therefore, we postulate with some caution that the incisor missing in Penthetor is il.

With respect to the upper dentition, only four cynopterine genera exhibit a single incisor: Alionycteris, Haplonycteris, Otopteropus, and Latidens. Based on comparisons of crown and root morphology with Aethalops alecto (fig. 13), the first three genera have apparently lost I1 and conserve a well-developed I2. Kock (1969a, 1969b) arrived at the same conclusions in the original descriptions of Alionycteris and Otopteropus. In Aethalops alecto, I 2 has a long, slightly divergent root, 

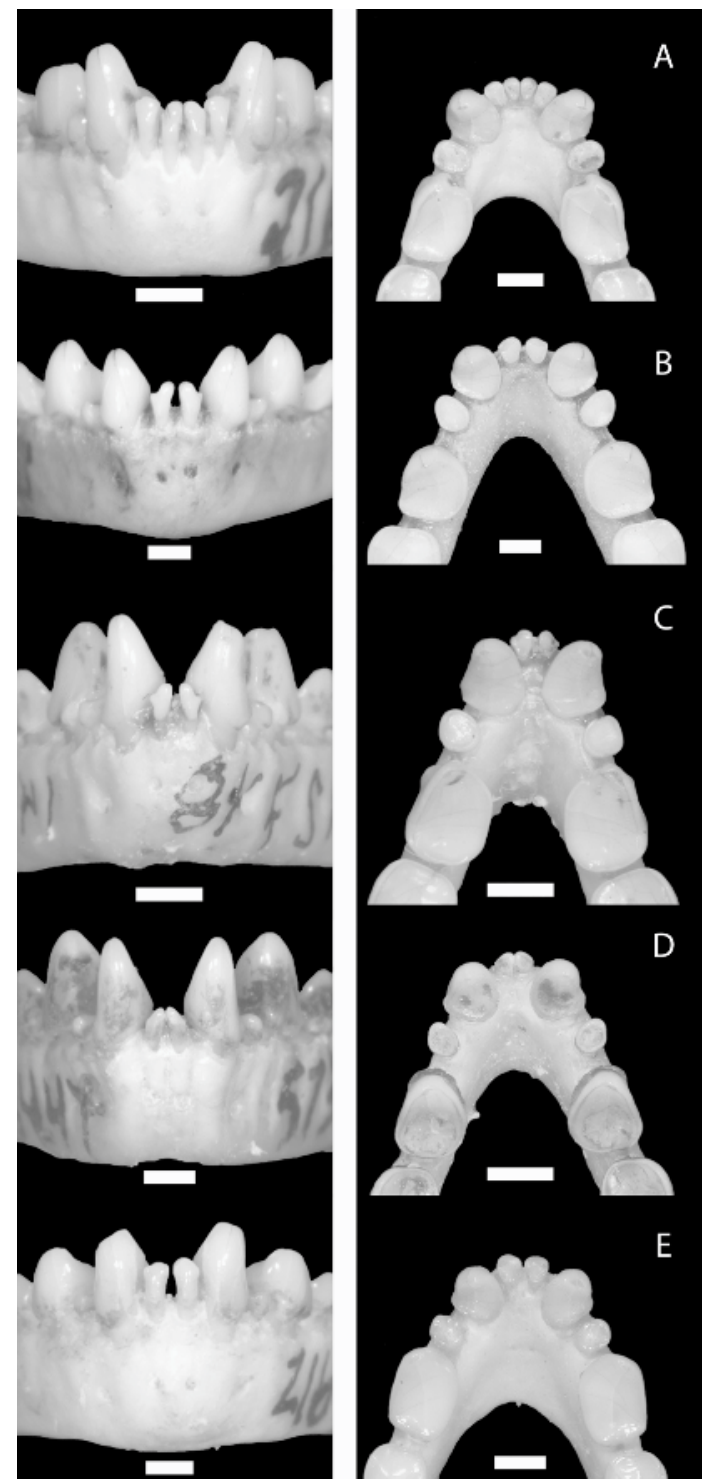

Fig. 8. Chironax melanocephalus AMNH 216739 (A), Aethalops alecto AMNH 216729 (B), Haplonycteris fischeri AMNH 142748 (C), Otopteropus cartilagonodus FMNH 573447 (D), and Balionycteris maculata AMNH 216755 (E), mental view of the mandible (left column) and occlusal view of the tip of the mandible (right column). Scales $=1 \mathrm{~mm}$.

and a long shaft bent in the middle of its length so that the apex of the tooth is directed medially (fig. 13A). By contrast, I1 is a cylindrical spicule thinner and shorter than I2. As described by Allen (1938), both upper incisors

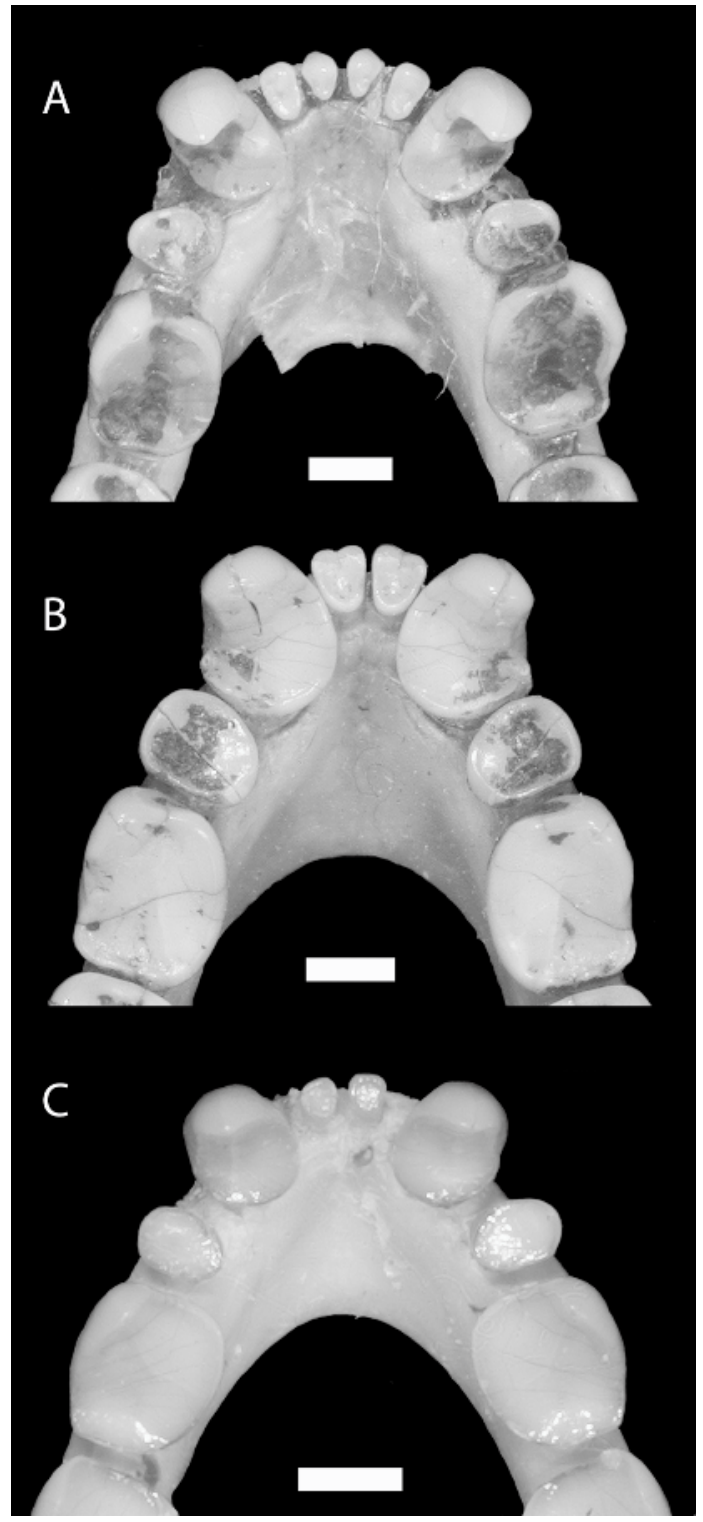

Fig. 9. Cynopterus brachyotis AMNH 222764 (A), Ptenochirus jagori AMNH 203262 (B), and Megaerops niphanae AMNH 238183 (C), occlusal view of the tip of mandible. Scales $=1 \mathrm{~mm}$.

are of approximately the same length in Aethalops aequalis; however, I1 is more slender than I2. It is therefore reasonable to conclude that $\mathrm{I} 1$ is in the process of reduction in Aethalops and may have been lost in the close relatives Alionycteris, Haplonycteris, and Otopteropus. Moreover, crown morphol- 


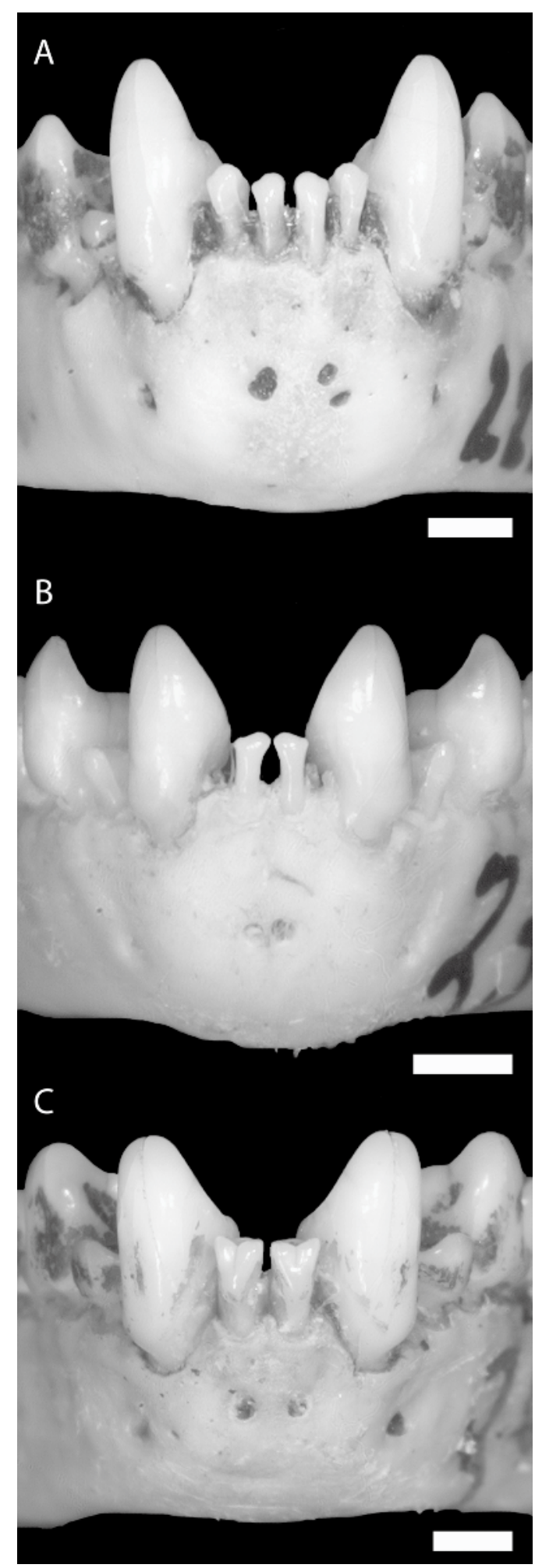

ogy of the single incisor in these three genera resembles the morphology of $\mathrm{I} 2$ in Aethalops (fig. 13). By contrast, Latidens, as compared with Thoopterus and Penthetor, has apparently retained I1 (I2 lost). In Thoopterus and Penthetor, I1 is long, cylindrical in cross section, and much larger than I2 (fig. 14A,B). The single incisor in Latidens also resembles the I1 of Thoopterus and Penthetor in having a short, straight root that does not diverge dorsolaterally (as does the root of $\mathrm{I} 2$ in Thoopterus and Penthetor, fig. 14, cf. A, B, and $\mathrm{C}$ ).

Nyctimenines, which exhibit a single upper incisor and no lower incisor, pose a more difficult problem. First, the single upper incisor is large, the root is long and straight, and the crown is sharply differentiated. The crown exhibits a unique triangular morphology that makes comparisons with other pteropodids, including cynopterines, difficult. Andersen (1912) considered the single incisor of nyctimenines to be homologous with the I1 of the cynopterines then known (to him, "Nyctimene undoubtedly is a genus of the Cynopterine group"; p. 685, footnote). However, as noted above, cynopterines that have a single upper incisor may retain either I1 or I2, and in some taxa (e.g., Aethalops alecto), I1 instead of I 2 is reduced (in contrast with the forms known to Andersen, in which I2 was always the smaller incisor when a size difference was present). In addition, recent phylogenetic analyses have shown that nyctimenines are not cynopterines but are instead relatively isolated, appearing as the most basal branch in the megachiropteran tree (Giannini and Simmons, 2005). This phylogenetic position offers no obvious candidates for morphological comparisons because the sister group of nyctimenines (the clade comprising all other megabats) is so large and diverse.

Leche (1878) first reported the presence of a single deciduous incisor in Nyctimene. We

Fig. 10. Cynopterus brachyotis AMNH 222764 (A), Megaerops niphanae AMNH 238183 (B), and Ptenochirus jagori AMNH 203262 (C), mental view of the mandible. Scales $=1 \mathrm{~mm}$. 


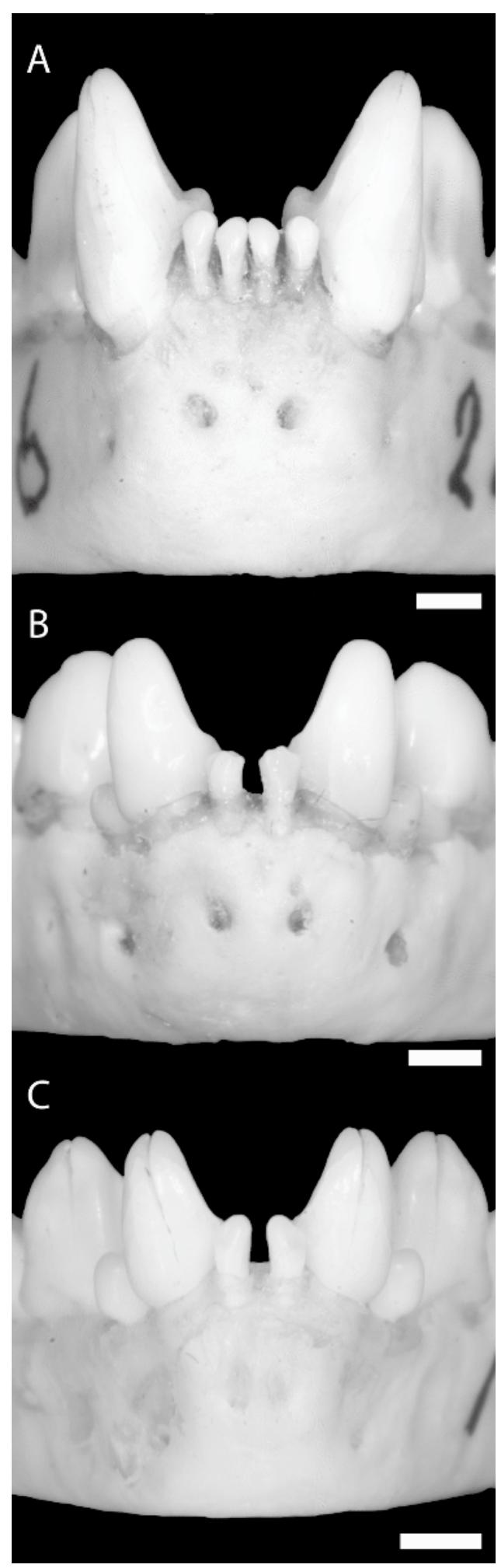

found a single deciduous incisor in both upper and lower tooth rows in $N$. major (AMNH 159295; fig. 15) and $N$. albiventer (AMNH 194849), as well as in Paranyctimene raptor (AMNH 198769). A one-to-one tooth replacement pattern is not helpful for determining the identity of the single incisor. Therefore, Andersen's (1912) hypothesis of homology (nyctimenines lost I2) can be neither corroborated nor rejected. No clear evidence from either tooth replacement or tooth morphology is available.

The genus Myonycteris seems particularly prone to dental anomalies, including aberrant incisors. Bergmans (1976) found supernumerary incisors in several Myonycteris torquata. The most remarkable case was the presence of a full second row of four incisors in front of the one typically present in an adult specimen; Bergmans (1976) discarded that the extra incisor row represented the retention of deciduous teeth on the basis of morphology of the elements. Another specimen lacked both I2. Myonycteris brachycephala (Bocage, 1889) is exceptional in that this species exhibits an asymmetric dental formula unique among heterodont mammals. Described as an individual anomaly (Andersen, 1912), the holotype (now lost) showed a total of three lower incisors instead of the normal four (i.e., i1 and i2 bilaterally present). Based on as many as 19 new specimens of this rare bat, Juste and Ibáñez (1993) demonstrated that the asymmetry in the incisor count is fixed in the species, so that one i1 is always missing and with similar frequency in the left and right mandible.

\section{CANINES}

In all megabats, both upper and lower canines are comparatively large and roughly conical in shape, and they are not displaced from the primitive mammalian position in either the upper and lower tooth rows (i.e., the

Fig. 11. Thoopterus nigrescens AMNH 196442 (A), Latidens salimalii HZM 1.26433 (B), and Penthetor lucasi AMNH 106826 (C), mental view of the mandible. Scales $=1 \mathrm{~mm}$. 


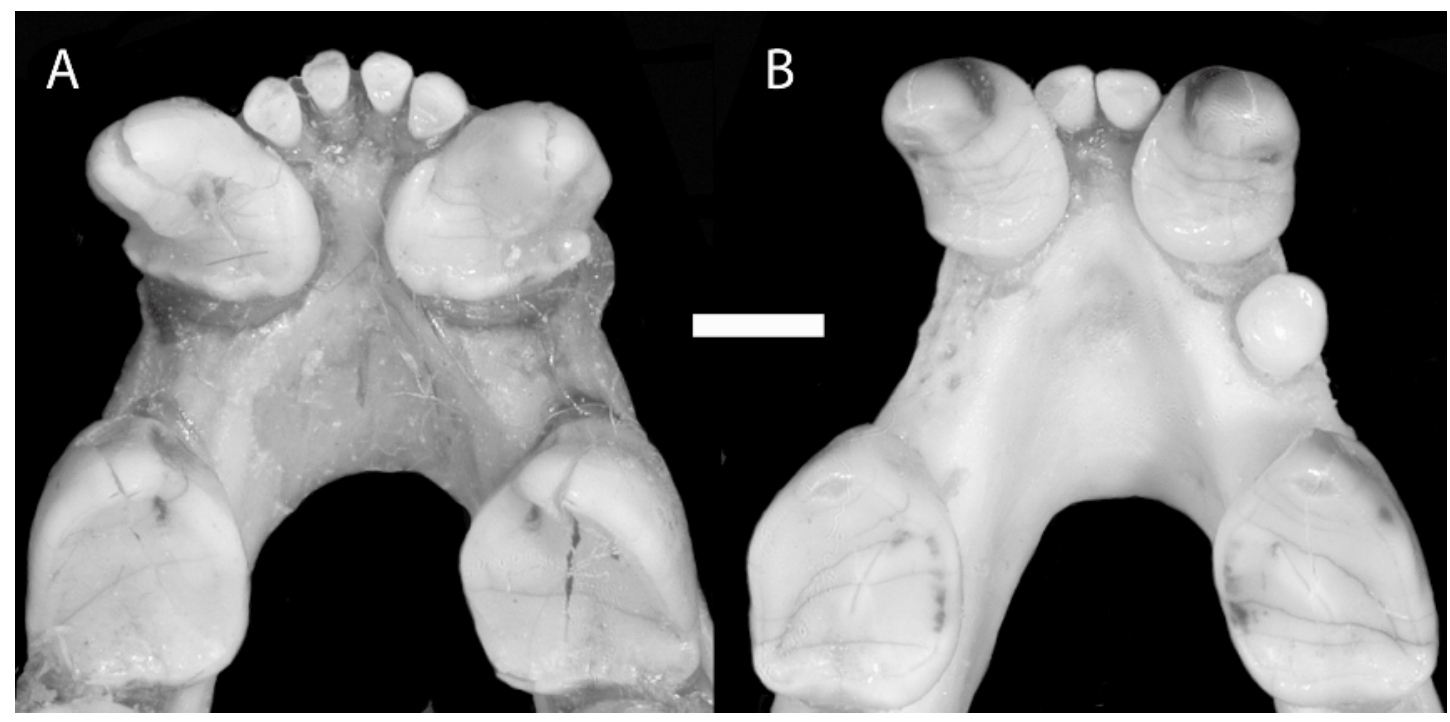

Fig. 12. Thoopterus nigrescens AMNH 222775 (A), and Latidens salimalii HZM 3.26435 (B), occlusal view of the tip of the mandible. Scale $=1 \mathrm{~mm}$.

upper canine emerges as the first maxillary tooth, the lower canine emerges in the rostral portion of the mandible and occludes in front of the upper canine). Therefore, element homology of megachiropteran canines remains unquestioned.

\section{Premolars}

All megachiropterans have two or three premolars in both the upper and lower dentition. When the complete set is present, a small anterior premolar (presumed to be P1/ p1) is followed in the tooth row by two large posterior premolars (presumed to be $\mathrm{P} 3 / \mathrm{p} 3$ and $\mathrm{P} 4 / \mathrm{p} 4)$. Tooth replacement evidence satisfactorily supports the hypothesis that the posterior premolars are the third and fourth, and these are always present in megachiropterans. Briefly, mammals such as carnivorans with four permanent premolars typically have three deciduous premolars, with the first permanent premolar lacking a deciduous predecessor (Miles and Grigson, 1990; Evans, 1993). Megabats therefore appear to have lost one permanent premolar and its deciduous predecessor, given that two deciduous premolars are replaced by two corresponding, large permanent elements (see Figs. 40-42 in
Giannini et al., 2006). The lost premolar is probably P2, because the two large posterior premolars are preceded and followed in the tooth row by elements without deciduous predecessor, i.e., by an anterior premolar (presumed P1) and a posterior molar (M1; see Giannini et al., 2006, for an example in Pteropus). Thus, the posterior premolars, always present in megachiropterans, likely are the third and fourth. These are frequently accompanied in the tooth row by a tooth that, based on the lack of deciduous predecessor, appears to be P1/p1.

However, the identity of the single anterior premolar has been contentious ( $\mathrm{p} 1 / \mathrm{P} 1$ or $\mathrm{p} 2 /$ P2?), and evidence other than tooth replacement is desirable. As noted previously, Miller (1907) assumed that the premolars missing in bats are p1 and P1, whereas Thomas (1908) rejected that hypothesis, instead arguing that the missing chiropteran premolar is P2/p2. Andersen (1908, 1912) emphatically supported Thomas's view with morphological evidence, including the following dental anomalies reported in his 1912 Catalogue. In Epomophorus gambianus BMNH 99.6.15.3, an extra tooth occupies the position of a $\mathrm{p} 2$ on both sides. The tooth is small and conical, and emerges from its own alveolus that completely 

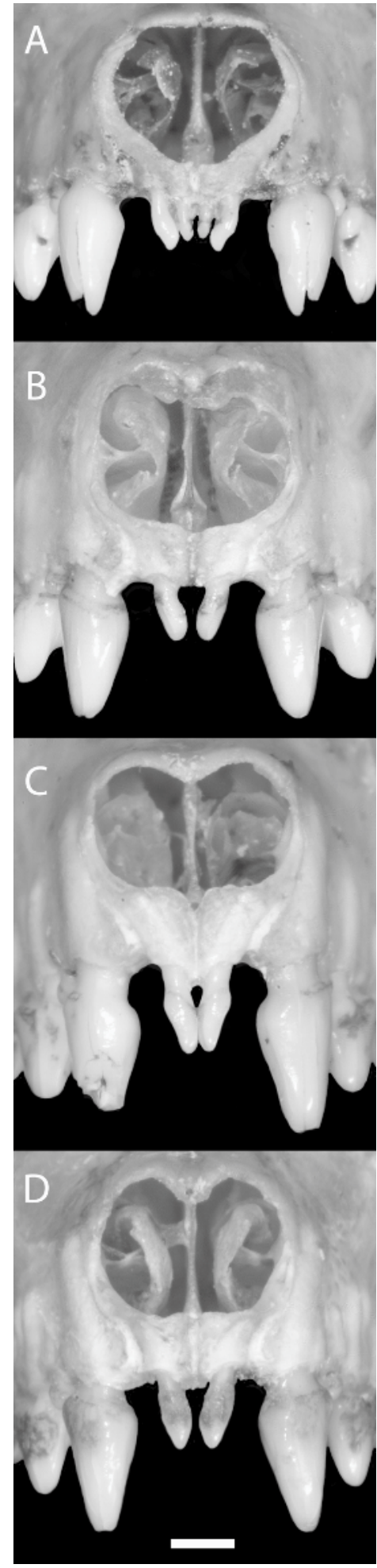

fills the space between the anterior and posterior teeth (identified as p1 and p3 by Andersen). The morphology of $\mathrm{p} 1$ and $\mathrm{p} 3$ is identical to the teeth seen in individuals with typical premolar count. A similar case exists in Pteropus scapulatus BMNH 86.11.1.1 (fig. 16). In this specimen, an extra premolar appears in the position of a p2 on the right side only. The p1 is normal except in that it appears displaced rostrally, closer to the canine on both sides, even when the extra tooth is present only on the right side (fig. 16). In normal individuals, $\mathrm{p} 1$ is closer to the center of the c-p3. An additional case in Eonycteris spelaea was reported by Andersen (1912). Therefore, the identity of the small anterior premolar as p1 seems reasonably established.

Although tooth replacement points to the same conclusion in the upper as well as the lower dentition, until now no anomaly-based evidence supported the hypothesis of retention of P1 as opposed to P2 in megabats. In the course of surveying megabat collections, we found a specimen of Myonycteris torquata (KMMA/MRAC 80.020-M-0001) that possesses four upper premolars (fig. 17A,B). This is a seemingly unique case in Megachiroptera. ${ }^{2}$ The first premolar in the KMMA/MRAC Myonycteris specimen closely resembles in size

\footnotetext{
${ }^{2}$ Among microchiropterans, the presence of a possible supernumerary $\mathrm{P} 2$ has been reported only in a few nectarfeeding phyllostomids (Lonchophylla, Lionycteris, Glossophaga, Lichonycteris, and Choeroniscus; Miles and Grigson, 1990) and in the frugivore Artibeus fimbriatus (Rui and Drehmer, 2004). However, these authors assumed the bat upper premolars to be P2, P3, and P4 (i.e., implicitly following Miller, 1907); in our view (i.e., following Thomas, 1908), the supernumerary premolar may instead be an atavistic P1 rather than a P2 in these microbats. If this is the case indeed, the KMMA/MRAC Myonycteris specimen remains the single bat to show an atavistic $\mathrm{P} 2$.
}

Fig. 13. Aethalops alecto AMNH 216729 (A), Alionycteris paucidentata FMNH 146599 (B), Haplonycteris fischeri AMNH 142748 (C), and Otopteropus cartilagonodus FMNH 573447 (D), rostral view of the skull apex showing the morphology of upper incisors. Note the divergent root of the second upper incisor of Aethalops and of the single upper incisor of Alionycteris, Haplonycteris, and Otopteropus. Scale $=1 \mathrm{~mm}$. 

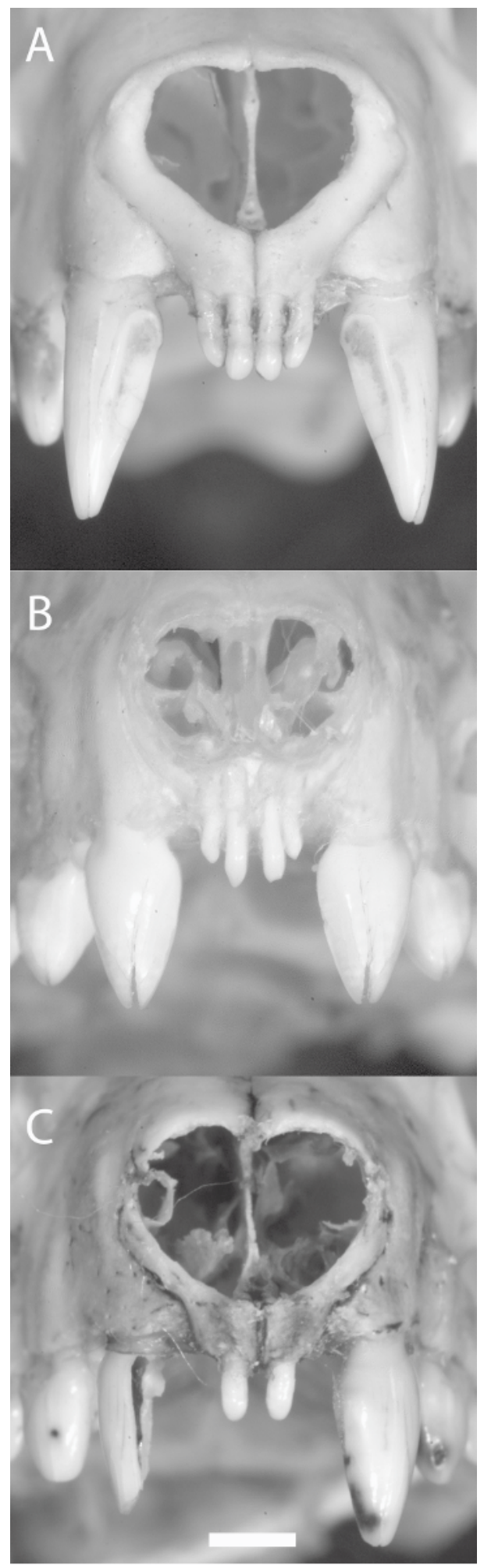

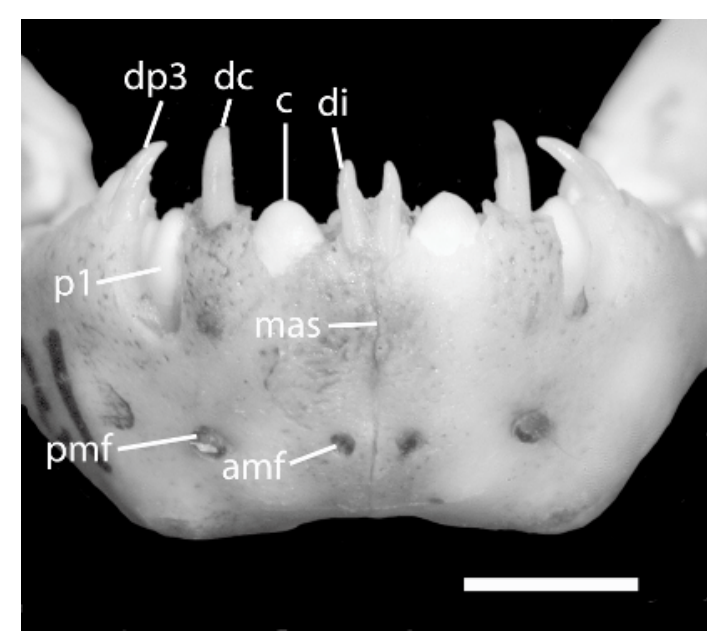

Fig. 15. Nyctimene major AMNH 159295, mandible, mental view showing the single lower deciduous incisor. Abbreviations: amf anterior mental foramen, c canine, dp3 deciduous third lower premolar, dc deciduous lower canine, di deciduous incisor, mas mandibular symphysis, p1 first lower premolar, pmf posterior mental foramen. Scale $=2 \mathrm{~mm}$.

and crown morphology the anterior premolar (putative P1) in Myonycteris specimens with typical premolar count (i.e., three elements as in M. torquata AMNH 236246 in fig. 17C,D). By contrast, the second premolar is smaller and appears simpler. In our interpretation, the atavism seen in the KMMA/MRAC specimen (retention of an ancestrally lost tooth with signs of reduction) provides anomaly-based evidence that $\mathrm{P} 1, \mathrm{P} 3$, and $\mathrm{P} 4$ are the premolars present in bats and that P2 is the missing chiropteran upper premolar.

Finally, an additional aspect in premolar count is specific element constancy. On one

Fig. 14. Thoopterus nigrescens AMNH 196442 (A), Penthetor lucasi AMNH 106826 (B), and Latidens salimalii HZM 3.26435 (C), rostral view of the skull apex showing the number and morphology of upper incisors. Note the straight root of the first upper incisor of Thoopterus and Penthetor and in the single upper incisor of Latidens. Scale $=2 \mathrm{~mm}$. 


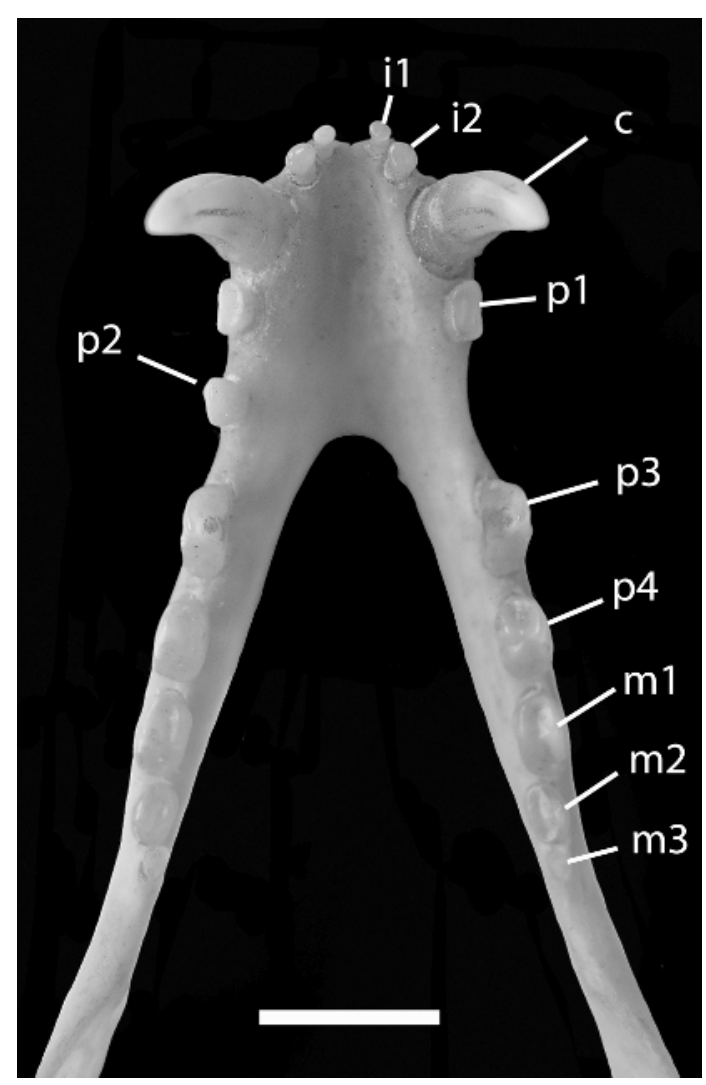

Fig. 16. Pteropus scapulatus BMNH 86.11.1.1, occlusal view of the mandible. An extra premolar appears in the position of a p2 on the right side. Position and morphology of the other teeth as well as the mandible are typical. Abbreviations: c lower canine, i1 first lower incisor, i2 second lower incisor, $\mathrm{m} 1$ first lower molar, $\mathrm{m} 2$ second lower molar, m3 third lower molar, p1 first lower premolar, p2 atavistic second lower premolar, p3 third lower premolar, p4, fourth lower premolar. Scale $=5 \mathrm{~mm}$.

hand, a trend exists toward the reduction and loss of the rudimentary P1 in pteropodine species. These premolars may not remain attached to their alveoli throughout the life of the individual, often being lost in adult individuals. For instance, in the majority of Pteropus species (with the notable exception of P. leucopterus; e.g., AMNH 187125; see Miller, 1907) P1 is a minute spicule that does not occlude with other teeth during mastication. The alveolus of P1 may or may not be perforated, so nutrient supply to the tooth may be compromised or interrupted. As a consequence, shedding this tooth is likely an ordinary process at least in Pteropus and Acerodon, probably reflecting a phase during the evolutionary process of tooth loss. The lack of normally present P1 have also been reported in some individuals of Myonycteris torquata (Bergmans, 1976). On the other hand, an extra premolar sometimes is present bilaterally in species in which most known individuals lack this element. This is the case of an extra P1 reported by Bergmans (1989) in Micropteropus pusillus (ZMA 15.852).

\section{MOLARS}

In pteropodids, $\mathrm{M} 1$ and $\mathrm{m} 1$ are always present, whereas $\mathrm{M} 2, \mathrm{~m} 2$, and $\mathrm{m} 3$ may experience degrees of reduction or be lost entirely. Reduction in crown size and loss of teeth in the molar tooth row always occurs from posterior to anterior. Among megabats only two genera, the cynopterines Haplonycteris and Otopteropus, lack both $\mathrm{m} 2$ and $\mathrm{m} 3$.

Many individual megachiropterans, particularly but not exclusively nectar feeding bats, show anomalies in molars, including supernumerary elements. Typically, a relatively small extra tooth occurs posterior to the last element commonly present in the species. The degree of reduction varies and is manifested in the crown structure, number and size of roots, and uni- or bilateral presence. Andersen (1912) reported a presumed $\mathrm{m} 4$ in some specimens of Pteropus giganteus (not seen by us) and Macroglossus minimus (BMNH 10.3.3.23) on one side, and Macroglossus minimus on both sides (not seen by us). In BMNH 10.3.3.23, the $\mathrm{m} 4$ is on the right side, double rooted, oval in shape, and ca. $5 \mathrm{~mm}$ in length. An additional specimen of Macroglossus minimus (BMNH 69.230, not reported by Andersen) shows a small (ca. $0.6 \mathrm{~mm}$ ) single-rooted $\mathrm{m} 4$ with an oval crown on the left side. Cases of unilateral and bilateral presence of $\mathrm{m} 4$ of small size were reported in Megaloglossus woermanni (Bergmans and van Bree, 1972) and Myonycteris torquata (Bergmans, 1976). Unilateral or bilateral absence of $\mathrm{m} 3$ has been also found in some specimens of Myonycteris torquata (Bergmans, 1976), a condition typical 


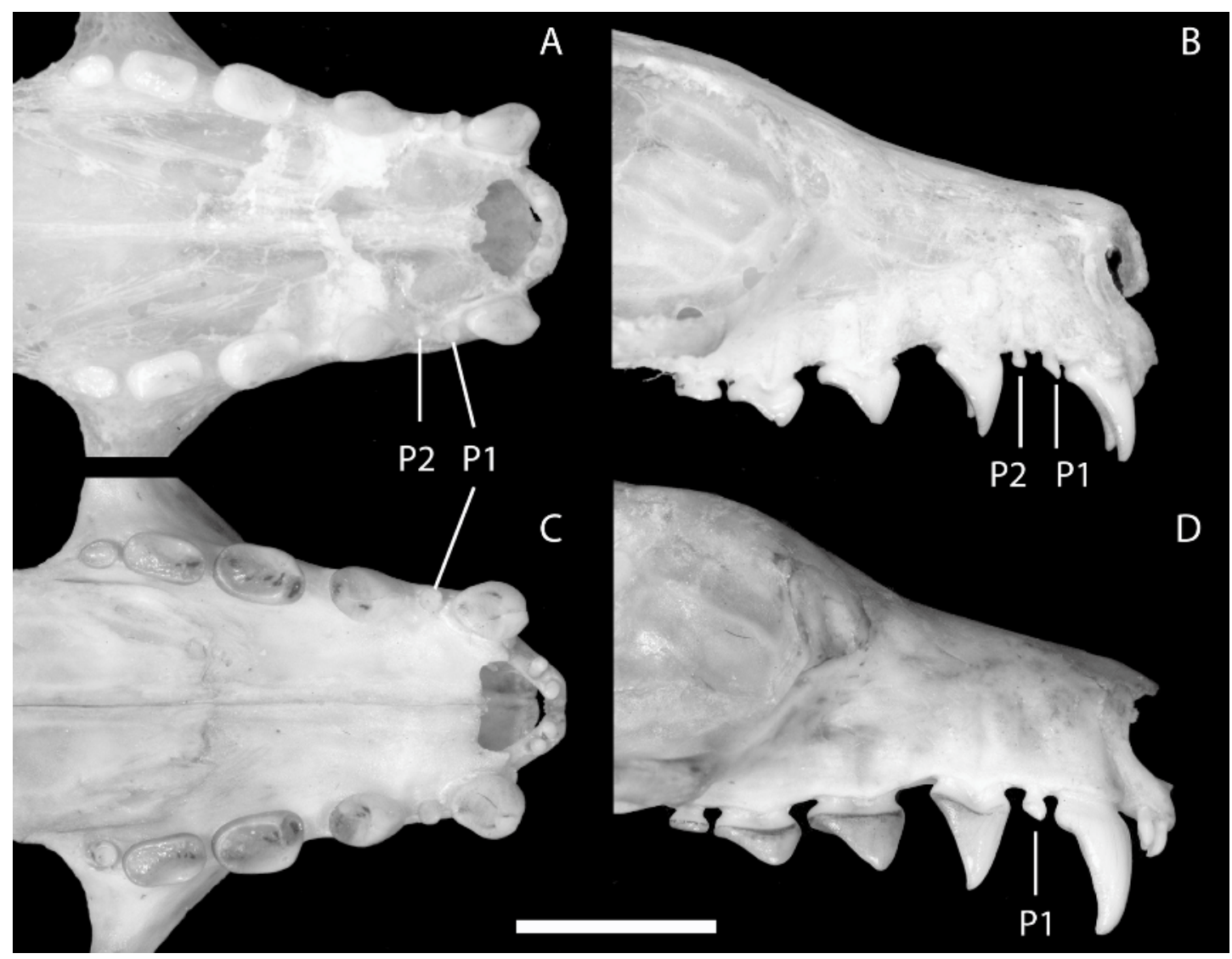

Fig. 17. Myonycteris torquata KMMA/MRAC 80.020-M-0001 (A, B) and M. torquata AMNH 236246 $(\mathbf{C}, \mathbf{D})$, ventral view of the palate $(\mathbf{A}, \mathbf{C})$ and lateral view of the rostrum $(\mathbf{B}, \mathbf{D})$. An extra premolar in the position of $\mathrm{P} 2$ is present in the KMMA/MRAC specimen. Abbreviations: $\mathrm{P} 1$ first upper premolar, P2 second upper premolar. Scale $=5 \mathrm{~mm}$.

of Myoncyteris relicta (Bergmans, 1980). We also found an $\mathrm{m} 3$ in Nyctimene albiventer (AMNH 198617; fig. 18), a species normally characterized by only two lower molars.

Regarding the upper dentition, no cases of presumed M4 are known in megabats, but an extra upper molar, M3, is common and a number of conditions were observed. In Macroglossus minimus, a double-rooted M3 is present on both sides in BMNH 10.4.7.2 and on the left side only in BMNH 10.3.3.23. Rousettus leschnaultii BMNH 95.7.27.1 exhibits a double-rooted M3 on the left side and a single-rooted M3 on the right side. A singlerooted M3 is present on both sides in another specimen of the same taxon (BMNH 4.4.9.2) and in one specimen of Megaloglossus woermani reported by Bergmans and van Bree (1972; MRAC 33371). A single-rooted M3 is present on one side in Eidolon helvum (BMNH unregistered, specimen identified with the code $\mathrm{c}^{3}$ ), Pteropus giganteus (BMNH 13.4.11.4), and Rousettus aegyptiacus (BMNH 37.4.28.67). This condition is reported also for Myonycteris torquata (Bergmans, 1976). Finally, Rousettus aegyptiacus BMNH 4.4.9.2 has single-rooted alveoli on both sides, the teeth having apparently been shed. Therefore, several degrees of development of the extra upper molar occur in isolated megachiropterans. Whereas most $\mathrm{M} 3 \mathrm{~s}$ are minute oval pegs, in $R$. leschnaultii BMNH 66.5490 the tooth is crescent-shaped 


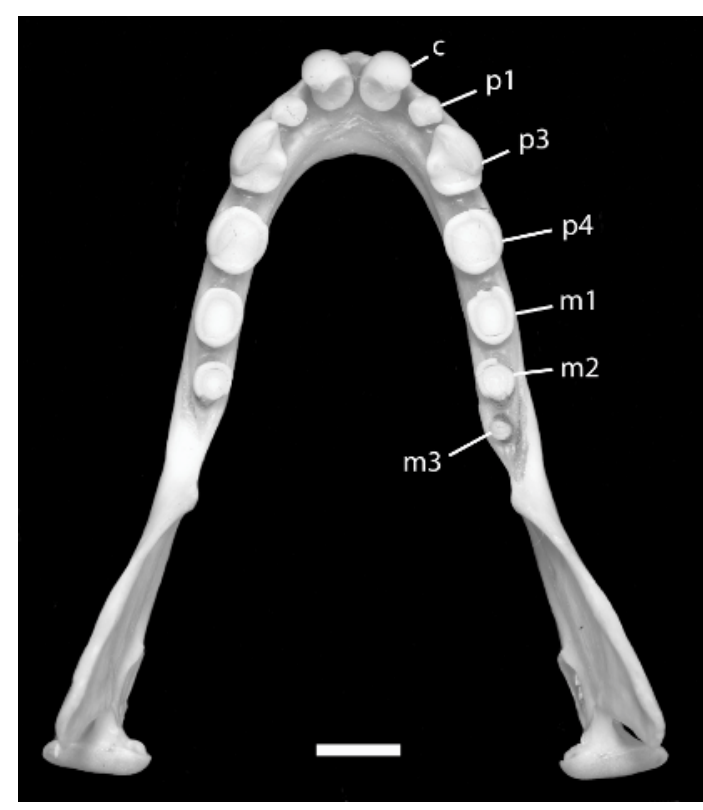

Fig. 18. Nyctimene albiventer AMNH 198617 , occlusal view of the mandible, presence of an extra lower molar (m3) in an otherwise typical mandible and dentition. Note the normal pattern of tooth wear in the dentition, which suggests that the extra tooth did not pose functional problems to the individual. Abbreviations: c lower canine, $\mathrm{m} 1$ first lower molar, $\mathrm{m} 2$ second lower molar, m3 atavistic third lower molar, p1 first lower premolar, p3 third lower premolar, p4 fourth lower premolar. Scale = $2 \mathrm{~mm}$.

and more robust. Finally, Bergmans (1976) reported unilateral and bilateral reduction or loss of M2 in some specimens of Myonycteris torquata.

\section{Preliminary Analysis of Phylogenetic Patterns}

A thorough analysis of the evolutionary pathways followed by the dentition in megachiropterans must wait until a broadly inclusive phylogeny of the family becomes available. However, a preliminary analysis is possible based on groups recovered in a recent phylogenetic analysis of megabats based on both molecular and morphological evidence (Giannini and Simmons, 2005). For dental characters, Giannini and Simmons (2005) used the same homology statements as in this contribution, but for a restricted taxonomic sampling (members of 26 genera were included out of 43 genera recognized by Simmons, 2005). While we work on increasing taxonomic and character sampling, here we use the available results to discuss two selected examples of possible phylogenetic patterns in dental formula evolution in megachiropterans. The following conclusions depend on the accuracy of the topology of Giannini and Simmons (2005).

Incisor variation across the phylogeny is illustrated in figure 19 (lower incisors) and figure 20 (upper incisors). In the lower incisor set, the variable presence of il creates an ambiguous pattern in the basal branches of the megachiropteran tree, including the ancestral node of the group (branches optimized $0 / 1$ in fig. 19). This is due to parallel losses or reacquisitions of il in nyctimenines, the two groups of cynopterines, and in harpyionycterines. The evolutionary pattern of i2 is simpler, with two losses (in nyctimenines and Aproteles bulmerae; black arrows in fig. 19), and one asymmetric loss in Myonycteris brachycephala (dotted arrow in fig. 19). In the case of the upper incisors, all changes are optimized as losses of an element. The first upper incisor (I1) is lost in harpyionycterines and Notopteris macdonaldi, as well as in the yinochiropteran outgroup taxa (fig. 20), whereas I2 is lost in nyctimenines and in Aproteles bulmerae, as well as in the outgroup Saccopteryx (black arrows in fig. 20). However, a denser taxonomic sampling, especially within cynopterines, is necessary in order to accommodate the observed variation (Table 1) in historical context because some combinations of incisor presence/ absence are not represented in this phylogenetic reconstruction because the Giannini and Simmons (2005) tree does not include all relevant taxa.

Basal megachiropterans exhibit reduced postcanine dentitions, and this generates ambiguity at basal nodes including the root of the megachiropteran tree. Optimization of the presence of $\mathrm{m} 3$ (fig. 21) and M2 (fig. 22) on Giannini and Simmons' (2005) optimal tree implies that these elements may either have been lost independently in several groups or their presence in higher clades is the product 
of a reversal. That is, megachiropterans either lost $\mathrm{m} 3$ and M2 ancestrally and reacquired them in higher clades through a reversal or ancestral megachiropterans possessed those teeth but later lost them independently in basal branches while preserving them (with some secondary losses) in higher clades. Regardless, there is little doubt that the constant presence of $\mathrm{M} 2$ in Balionycteris represents a reversal, as this genus is deeply nested up within a clade composed of cynopterines that lack M2 (fig. 22).

\section{Reversals, Anomalies, and Dental FIELD THEORY}

Reversals of long-lost structures including teeth are known to occur in mammals. In principle, reversals imply the rejection of primary homology. For instance, in Lynx (Carnivora, Felidae) M2 reappeared after being lost in the felid lineage since the Miocene (Marshall et al., 1994). Regaining M2 in Lynx likely involved a change in the genetic control of the molarization field (Marshall et al., 1994). This does not require the dismissal of M2 homology in Lynx as compared to other mammals. Briefly, the dental field theory postulates the existence of three fields, the incisivization, caninization, and molarization fields, which regulate the expression of individual teeth in each of the regions of the mandibular arch (for details, see Miles and Grigson, 1990). The fields are represented as a sinusoid of varying strengths of the genetic signal affecting the primordial alveolar surface of the maxilla and mandible. Tooth count is a precise meristic variable, and each signal peak corresponds topographically with the position of a specific tooth with defined identity. The local field signal stimulates cell condensations to develop into a tooth bud from which a deciduous or permanent tooth is finally formed. The program for building an individual tooth (involving $>50$ structural genes in molars of mice; Workman et al., 2002) is triggered when a threshold level of realization is surpassed (Marshall et al., 1994).

Interpreting the case of the reversed M2 under the dental field theory, a reactivation of the molarization signal in the caudal portion of the primordial maxilla is likely responsible for the ordinary presence of $\mathrm{M} 2$ in Balionycteris (and Lynx). This hypothesis implies that structural genes responsible for tooth development are not lost but only suppressed in megabats that lack M2 and other teeth, like some incisors in cynopterines. Thus, the reversed M2 in Balionycteris is itself homologous to a M2 primitively present (e.g., in Rousettus), so what varies across taxa is the strength of the local field signal (Marshall et al., 2004).

In our view, the molarization field also provides a mechanism to explain the high frequency of meristic anomalies in molars of nectarivores (macroglossines [see Andersen, 1912] but also in New World phyllostomid nectarivores, Glossophagini and Lonchophylini [Miles and Grigson, 1990]). If bats are strongly dependent on the occlusion pattern of their molars to process food, there should be a strong selection favoring an orderly expression of a specific molarization field. But if bats do not depend much on their molars for food processing, as is the case in nectarivores, a weakening and/or relaxation in the control of the molarization field need not be severely penalized by selection. As a result, anomalies in dental formulae may be common in nectarivores.

The case of the São Thomé endemic Myonycteris brachycephala, of which all known specimens lack either the right or left i1 (Juste and Ibáñez, 1993), exposes an easily overlooked aspect of dental development: symmetry. We agree with Juste and Ibáñez (1993) that fixation of dental asymmetry in $M$. brachycephala is likely to be a nondeleterious consequence of a population bottleneck originating from the colonization of a small oceanic island. We further postulate that two other, more proximal processes are involved: a weakening of the rostral end of the lower incisivization field (resulting in the systematic lack of either the right or left i1) and a failure of bilateral control of symmetry. Given that the remainder of the dentition is normally expressed in $M$. brachycephala, these two processes appear to be local in nature, requiring the existence of multiple regional controls of both expression and symmetry along the dental field. 


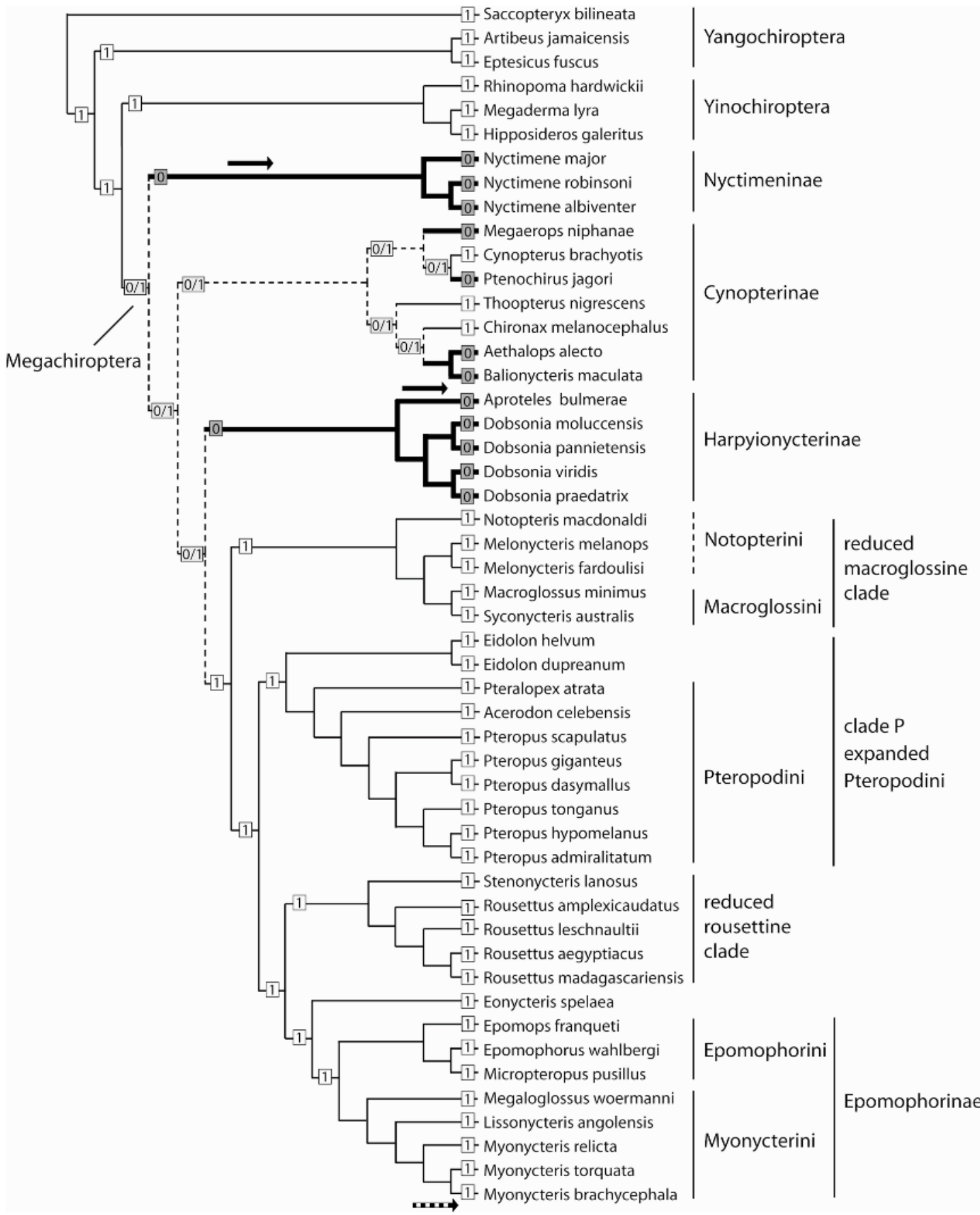

Fig. 19. Optimization of the absence [0] and presence [1] of lower incisors in megabats, using the optimal tree from the combined analysis of Giannini and Simmons (2005; modified from their fig. 7). Optimization of the absence/presence of il absence/presence is represented along the branches, with ambiguous branches dotted. Optimization of the absence/presence of i2 is shown with black arrows representing a $1 \rightarrow 0$ transformation (loss of i2). The dotted arrow indicates the asymmetric loss of one first lower incisor in Myonycteris brachycephala. 


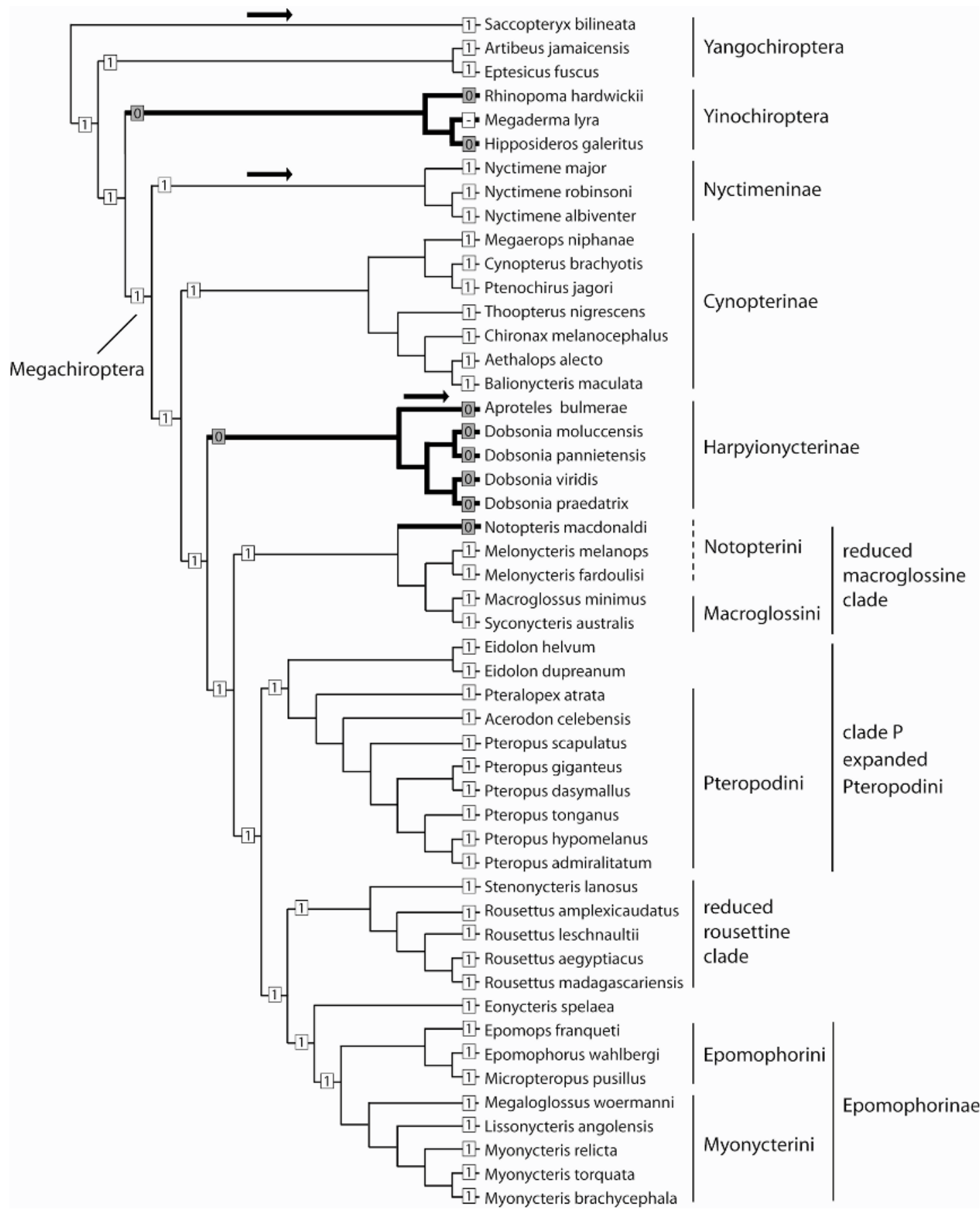

Fig. 20. Optimization of the absence [0] and presence [1] of upper incisors in megabats, using the optimal tree from the combined analysis of Giannini and Simmons (2005; modified from their fig. 7). Optimization of the absence/presence of I1 absence/presence is represented along the branches. Optimization of the absence/presence of I 2 is shown with black arrows representing a $1 \rightarrow 0$ transformation (loss of I2). Absence/ presence of both I1 and I 2 is inapplicable in the outgroup Megaderma lyra as this bat lacks the premaxillary bone that supports the upper incisors when present. 


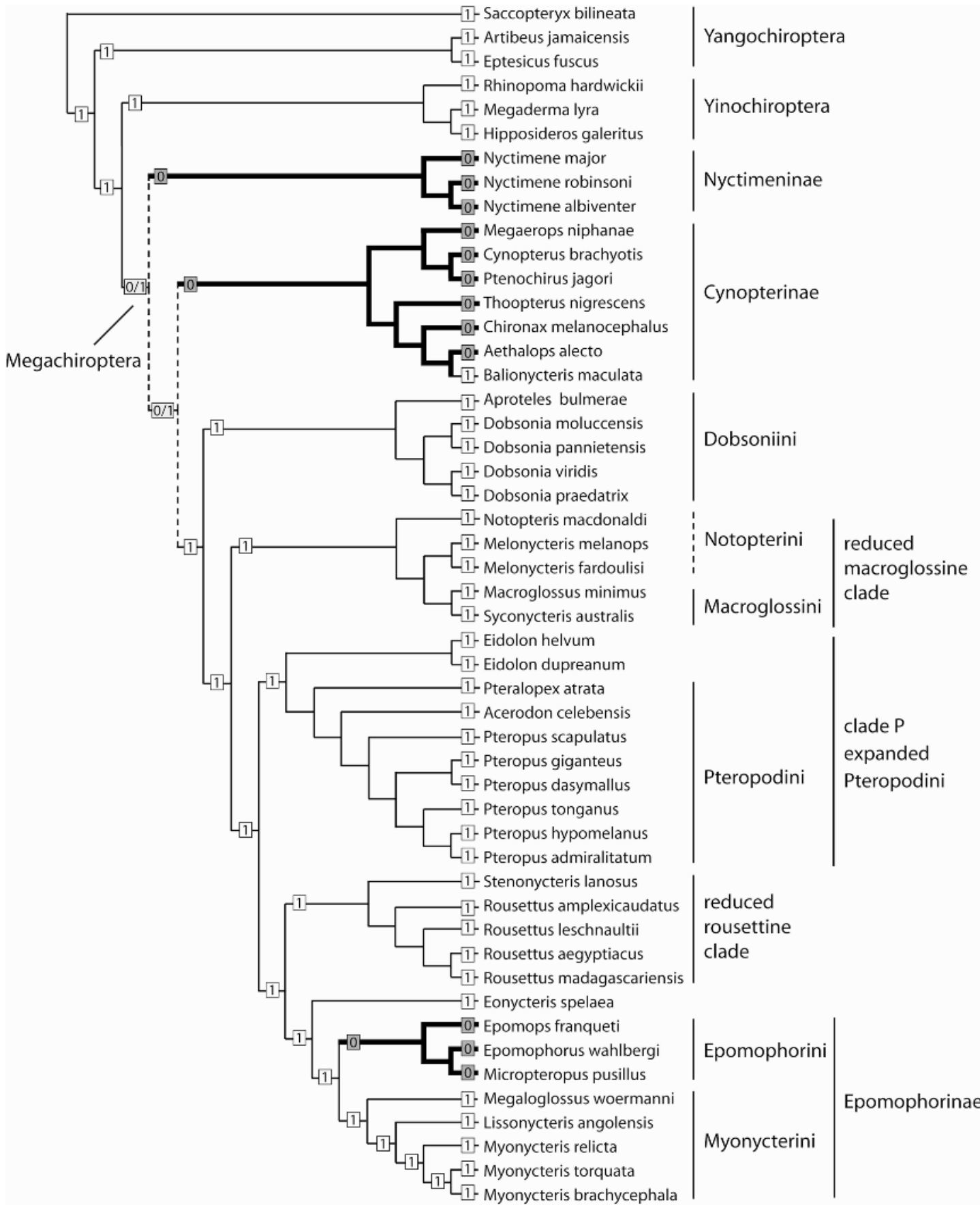

Fig. 21. Optimization of the absence [0] and presence [1] of $\mathrm{m} 3$ in the optimal tree from the combined analysis of Giannini and Simmons (2005; modified from their fig. 7). Dotted branches connect nodes with ambiguous final assignments [0/1]. Some internal node assignments are omitted for clarity. 


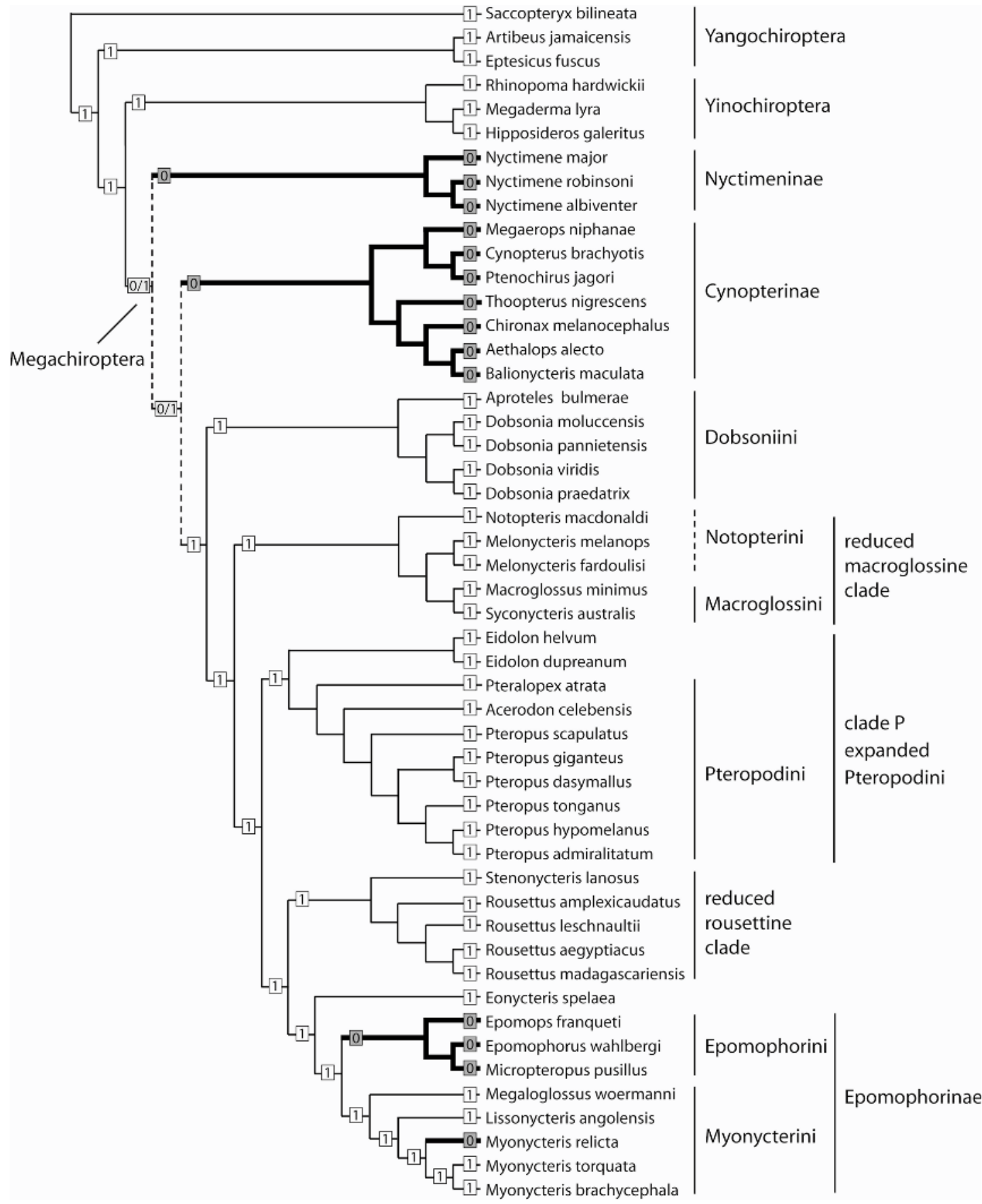

Fig. 22. Optimization of the absence [0] and presence [1] of $\mathrm{M} 2$ in the optimal tree from the combined analysis of Giannini and Simmons (2005; modified from their fig. 7). Dotted branches connect nodes with ambiguous final assignments [0/1]. Some internal node assignments are omitted for clarity. 
TABLE 2

Element Homology of Each Tooth Proposed in the Present Study for Each Currently Recognized Genus of Megachiropteran Bat ${ }^{\mathrm{a}}$

\begin{tabular}{|c|c|c|c|c|c|c|c|c|c|c|c|c|c|c|c|c|c|c|}
\hline \multirow[b]{2}{*}{ Subfamily } & \multirow[b]{2}{*}{ Genus } & \multicolumn{9}{|c|}{ Lower dentition } & \multicolumn{8}{|c|}{ Upper dentition } \\
\hline & & i1 & i2 & $\mathrm{c}$ & $\mathrm{p} 1$ & p3 & & $\mathrm{m} 1$ & $\mathrm{~m} 2$ & $\mathrm{~m} 3$ & I1 & $\mathrm{I} 2$ & $\mathrm{C}$ & $\mathrm{P} 1$ & P3 & P4 & M1 & M2 \\
\hline \multirow[t]{2}{*}{ Nyctimeninae } & Nyctimene & 0 & 0 & 1 & 1 & 1 & 1 & 1 & 1 & 0 & $1 ?$ & 0 ? & 1 & 1 & 1 & 1 & 1 & 0 \\
\hline & Paranyctimene & 0 & 0 & 1 & 1 & 1 & 1 & 1 & 1 & 0 & $1 ?$ & 0 ? & 1 & 1 & 1 & 1 & 1 & 0 \\
\hline \multirow[t]{14}{*}{ Cynopterinae } & Aethalops & 1 & 0 & 1 & 1 & 1 & 1 & 1 & 1 & 0 & 1 & 1 & 1 & 1 & 1 & 1 & 1 & 0 \\
\hline & Alionycteris & 1 & 0 & 1 & 1 & 1 & 1 & 1 & (1) & 0 & 0 & 1 & 1 & 1 & 1 & 1 & 1 & 0 \\
\hline & Balionycteris & 0 & 1 & 1 & 1 & 1 & 1 & 1 & 1 & 0 & 1 & 1 & 1 & 1 & 1 & 1 & 1 & 1 \\
\hline & Chironax & 1 & 1 & 1 & 1 & 1 & 1 & 1 & 1 & 0 & 1 & 1 & 1 & 1 & 1 & 1 & 1 & 0 \\
\hline & Cynopterus & 1 & 1 & 1 & 1 & 1 & 1 & 1 & 1 & 0 & 1 & 1 & 1 & 1 & 1 & 1 & 1 & 0 \\
\hline & Dyacopterus & 1 & 1 & 1 & 1 & 1 & 1 & 1 & 1 & 0 & 1 & 1 & 1 & 0 & 1 & 1 & 1 & 0 \\
\hline & Haplonycteris & 1 & 0 & 1 & 1 & 1 & 1 & 1 & 0 & 0 & 0 & 1 & 1 & 1 & 1 & 1 & 1 & 0 \\
\hline & Latidens & 0 & 1 & 1 & 1 & 1 & 1 & 1 & 1 & 0 & 1 & 0 & 1 & 1 & 1 & 1 & 1 & 0 \\
\hline & Megaerops & 0 & 1 & 1 & 1 & 1 & 1 & 1 & 1 & 0 & 1 & 1 & 1 & 1 & 1 & 1 & 1 & 0 \\
\hline & Otopteropus & 1 & 0 & 1 & 1 & 1 & 1 & 1 & 0 & 0 & 0 & 1 & 1 & 1 & 1 & 1 & 1 & 0 \\
\hline & Penthetor & 0 & 1 & 1 & 1 & 1 & 1 & 1 & 1 & 0 & 1 & 1 & 1 & 1 & 1 & 1 & 1 & 0 \\
\hline & Ptenochirus & 0 & 1 & 1 & 1 & 1 & 1 & 1 & 1 & 0 & 1 & 1 & 1 & 1 & 1 & 1 & 1 & 0 \\
\hline & Sphaerias & 1 & 1 & 1 & 1 & 1 & 1 & 1 & 1 & 0 & 1 & 1 & 1 & 1 & 1 & 1 & 1 & 0 \\
\hline & Thoopterus & 1 & 1 & 1 & 1 & 1 & 1 & 1 & 1 & 0 & 1 & 1 & 1 & 1 & 1 & 1 & 1 & 0 \\
\hline \multirow[t]{3}{*}{ Harpyionycterinae } & Aproteles & 0 & 0 & 1 & 0 & 1 & 1 & 1 & 1 & 1 & 0 & 0 & 1 & 1 & 1 & 1 & 1 & 1 \\
\hline & Dobsonia & 0 & 1 & 1 & 1 & 1 & 1 & 1 & 1 & 1 & 0 & 1 & 1 & 0 & 1 & 1 & 1 & 1 \\
\hline & Harpyionycteris & $0 ?$ & $1 ?$ & 1 & 1 & 1 & 1 & 1 & 1 & 1 & 0 ? & $1 ?$ & 1 & 1 & 1 & 1 & 1 & 1 \\
\hline \multirow[t]{5}{*}{ Macroglossinae } & Macroglossus & 1 & 1 & 1 & 1 & 1 & 1 & 1 & 1 & 1 & 1 & 1 & 1 & 1 & 1 & 1 & 1 & 1 \\
\hline & Melonycteris & 0 & 1 & 1 & 1 & 1 & 1 & 1 & 1 & 1 & 1 & 1 & 1 & 1 & 1 & 1 & 1 & 1 \\
\hline & M. melanops & 1 & 1 & 1 & 1 & 1 & 1 & 1 & 1 & 1 & 1 & 1 & 1 & 1 & 1 & 1 & 1 & 1 \\
\hline & Notopteris & 0 & 1 & 1 & 0 & 1 & 1 & 1 & 1 & 1 & 0 & 1 & 1 & 0 & 1 & 1 & 1 & 1 \\
\hline & Syconycteris & 1 & 1 & 1 & 1 & 1 & 1 & 1 & 1 & 1 & 1 & 1 & 1 & 1 & 1 & 1 & 1 & 1 \\
\hline \multirow[t]{7}{*}{ Pteropodinae } & Acerodon & 1 & 1 & 1 & 1 & 1 & 1 & 1 & 1 & 1 & 1 & 1 & 1 & (1) & 1 & 1 & 1 & 1 \\
\hline & Mirimiri & 1 & 1 & 1 & 1 & 1 & 1 & 1 & 1 & 1 & 1 & 1 & 1 & 1 & 1 & 1 & 1 & 1 \\
\hline & Neopteryx & 1 & 1 & 1 & 1 & 1 & 1 & 1 & 1 & 1 & 1 & 1 & 1 & 0 & 1 & 1 & 1 & 1 \\
\hline & Pteralopex & 1 & 1 & 1 & 1 & 1 & 1 & 1 & 1 & 1 & 1 & 1 & 1 & 1 & 1 & 1 & 1 & 1 \\
\hline & Pteropus & 1 & 1 & 1 & 1 & 1 & 1 & 1 & 1 & 1 & 1 & 1 & 1 & (1) & 1 & 1 & 1 & 1 \\
\hline & Styloctenium & 0 & 1 & 1 & 1 & 1 & 1 & 1 & 1 & 1 & 1 & 1 & 1 & 1 & 1 & 1 & 1 & 1 \\
\hline & *Eidolon & 1 & 1 & 1 & 1 & 1 & 1 & 1 & 1 & 1 & 1 & 1 & 1 & 1 & 1 & 1 & 1 & 1 \\
\hline \multirow[t]{3}{*}{ Rousettinae } & Rousettus & 1 & 1 & 1 & 1 & 1 & 1 & 1 & 1 & 1 & 1 & 1 & 1 & 1 & 1 & 1 & 1 & 1 \\
\hline & R. (Boneia) bidens & 1 & 1 & 1 & 1 & 1 & 1 & 1 & 1 & 1 & (0) & 1 & 1 & 1 & 1 & 1 & 1 & 1 \\
\hline & ${ }^{*}$ Eonycteris & 1 & 1 & 1 & 1 & 1 & 1 & 1 & 1 & 1 & 1 & 1 & 1 & 1 & 1 & 1 & 1 & 1 \\
\hline \multicolumn{19}{|l|}{ Epomophorinae } \\
\hline \multirow[t]{2}{*}{ Scotonycterini } & Casinycteris & 1 & 1 & 1 & 1 & 1 & 1 & 1 & 1 & 0 & 1 & 1 & 1 & 0 & 1 & 1 & 1 & 0 \\
\hline & Scotonycteris & 1 & 1 & 1 & 1 & 1 & 1 & 1 & 1 & 0 & 1 & 1 & 1 & 0 & 1 & 1 & 1 & 0 \\
\hline Plerotini & Plerotes & 1 & 1 & 1 & 1 & 1 & 1 & 1 & 1 & 1 & 1 & 1 & 1 & 1 & 1 & 1 & 1 & (1) \\
\hline \multirow[t]{5}{*}{ Epomophorini } & Epomophorus & 1 & 1 & 1 & 1 & 1 & 1 & 1 & 1 & 0 & 1 & 1 & 1 & 0 & 1 & 1 & 1 & 0 \\
\hline & Epomops & 1 & 1 & 1 & 1 & 1 & 1 & 1 & 1 & 0 & 1 & (1) & 1 & 0 & 1 & 1 & 1 & 0 \\
\hline & Hypsignathus & 1 & 1 & 1 & (1) & 1 & 1 & 1 & 1 & 0 & 1 & 1 & 1 & 0 & 1 & 1 & 1 & 0 \\
\hline & Micropteropus & 1 & 1 & 1 & 1 & 1 & 1 & 1 & 1 & 0 & 1 & 1 & 1 & 0 & 1 & 1 & 1 & 0 \\
\hline & Nanonycteris & 1 & 1 & 1 & 1 & 1 & 1 & 1 & 1 & 0 & 1 & 1 & 1 & 0 & 1 & 1 & 1 & 0 \\
\hline \multirow[t]{5}{*}{ Myonycterini } & Lissonycteris & 1 & 1 & 1 & 1 & 1 & 1 & 1 & 1 & 1 & 1 & 1 & 1 & 1 & 1 & 1 & 1 & 1 \\
\hline & Megaloglossus & 1 & 1 & 1 & 1 & 1 & 1 & 1 & 1 & 1 & 1 & 1 & 1 & 1 & 1 & 1 & 1 & 1 \\
\hline & Myonycteris & 1 & 1 & 1 & 1 & 1 & 1 & 1 & 1 & 1 & 1 & 1 & 1 & 1 & 1 & 1 & 1 & 1 \\
\hline & M. relicta & 1 & 1 & 1 & 1 & 1 & 1 & 1 & 1 & 0 & 1 & 1 & 1 & 1 & 1 & 1 & 1 & 1 \\
\hline & M. brachycephala & [1] & 1 & 1 & 1 & 1 & 1 & 1 & 1 & 0 & 1 & 1 & 1 & 1 & 1 & 1 & 1 & 1 \\
\hline
\end{tabular}


TABLE 2

(Continued)

\begin{abstract}
"Tooth presence $=$ " 1 " and tooth absence $=$ " $0 "$ ". All conditions are specified in genera with more than one dental formula (Melonycteris, Myonycteris, and Rousettus). Homology statements uncorroborated in the present study are indicated "?" (in Nyctimene and Harpyionycteris). Parenthetical and bracket indications include: "(1)" a tooth that is frequently shed in fully adult specimens (e.g., m2 of Alionycteris); "(0)" a tooth that is more frequently absent than present (Rousettus (Boneia) bidens); "[1]" a tooth always present in one side only (Myonycteris brachycephala). Genera are allocated to subfamilies on the basis of a combination of sources (Bergmans, 1997; Giannini and Simmons, 2005; Giannini et al., 2006). The taxonomic status of two genera (Eidolon and Eonycteris) is not clearly established (indicated by asterisks, *). Abbreviations: i1, first lower incisor; i2, second lower incisor; c, lower canine; p1, first lower premolar; p3, third lower premolar; $\mathrm{p} 4$, fourth lower premolar; $\mathrm{m} 1$, first lower molar; $\mathrm{m} 2$, second lower molar; $\mathrm{m} 3$, third lower molar; I1, first upper incisor; I2, second upper incisor; C, upper canine; P1, first upper premolar; P3, third upper premolar; P4, fourth upper premolar; M1, first upper molar; M2, second upper molar.
\end{abstract}

\section{CONCLUSIONS}

In the light of our analysis, which included comparisons of morphology, tooth replacement, and dental anomalies observed in representatives of all megachiropteran genera, we presented evidence that confirms the generalized megachiropteran dental formula (34 teeth, I1, I2, C, P1, P3, P4, M1, M2, i1, i2, c, p1, p3, $\mathrm{p} 4, \mathrm{~m} 1, \mathrm{~m} 2$, and $\mathrm{m} 3$ present) and establishes the homology of each tooth in most megachiropteran taxa that have less than 34 teeth. In most (but not all) cases in which reduction in tooth number has taken place, our conclusions confirm presumed homologies of the remaining teeth as postulated by previous authors, particularly Andersen (1908, 1912). Table 2 lists the homology statements proposed here for all combinations of species-specific megachiropteran variations in tooth number.

Through our analyses, we reduced the untested element homology assumptions in megabats to just two cases, i.e., the identity of single incisors in Harpyionycteris and in nyctimenines. We consider the former to be relatively unproblematic because our comparisons are supported by phylogenetic relationships. Furthermore, the homologies we propose could be tested in the future with juvenile specimens of Harpyionycteris collected at the stage of deciduous tooth replacement. The case of nyctimenines is more difficult due to the reduction to a single deciduous incisor. For tooth replacement evidence to be significant in clarifying the homologies of this tooth in nyctimenines, anomalous individuals with two pairs of upper deciduous incisors would need to be collected; so, unlike the case of
Harpyionycteris, tooth replacement evidence is not likely available in the normal populations.

It is interesting to note that Nyctimene and Paranyctimene lack permanent lower incisors, but exhibit a single lower deciduous incisor (fig. 15). This supports the idea that in megachiropterans (including these taxa and Dobsonia) the deciduous dentition tends to be more conservative than the permanent dentition. Thus, homologies based on tooth replacement may be considered reliable due to the consistent deciduous/permanent reduction pattern across genera.

Preliminary mapping of dental characters on phylogenetic trees reveal some interesting evolutionary patterns despite some ambiguity and homoplasy. Examples include convergence in tooth loss inferred to have occurred in Asian cynopterines and nyctimenines and in African epomophorines, and reversals manifested in the reappearance of elements lost in ancestral lineages. Reversals, atavistic numeral anomalies, and asymmetries are satisfactorily explained by the dental field theory. The field concept suggests that a tooth at a given position may be considered homologous even if it exhibits multiple originations on a phylogeny, placing the homoplastic component of variation in the expression/suppression pattern of the element. That is, element homology is supported by structural genes, whereas element realization (coded as presence/absence of the element) depends on regulatory genes.

\section{ACKNOWLEDGMENTS}

We are thankful to Wim Bergmans and Kris Helgen for a thorough review of this manu- 
script and thoughtful comments. We thank Paula Jenkins (Natural History Museum, London), Lawrence Heaney (Field Museum of Natural History, Chicago), Paul Bates (Harrison Zoological Museum, Sevenoaks, UK), and Emanuel Gilissen and Wim Wendelen (Koninklijk Museum voor Midden-Africa/Musée Royal de l'Afrique Centrale, Tervuren, Belgium) for access to specimens under their care. Funding for this report was provided by National Science Foundation (grants DEB-9873663 and EF0629811 to N.B.S.) and Coleman and Vernay postdoctoral fellowships at the AMNH to N.P.G.

\section{REFERENCES}

Allen, G.M. 1916. Bats of the genus Corynorhinus. Bulletin of the Museum of Comparative Zoology Harvard 60: 333-356.

Allen, G.M. 1938. A new pygmy fruit bat from Borneo. Journal of Mammalogy 19: 496-498.

Andersen, K. 1908. A monograph of the chiropteran genera Uroderma, Enchisthenes, and Artibeus: Proceedings of the Zoological Society of London 1908: 204-319.

Andersen, K. 1912. Catalogue of the Chiroptera in the collection of the British Museum. Volume I: Megachiroptera. London: Trustees British Museum (Natural History).

Bates, P.J.J., and D.L. Harrison. 1997. Bats of the Indian subcontinent Sevenoaks, United Kingdon: Harrison Zoological Museum.

Bergmans, W. 1976. A revision of the African genus Myonycteris Matschie, 1899 (Mammalia, Megachiroptera). Beaufortia 24(317): 189-216.

Bergmans, W. 1980. A new fruit bat of the genus Myonycteris Matschie, 1899, from Eastern Kenya and Tanzania (Mammalia, Megachiroptera). Zoologische Mededelingen 55(14): 171-181.

Bergmans, W. 1989. Taxonomy and biogeography of African fruit bats (Mammalia, Megachiroptera). 2. The genera Micropteropus Matschie, 1899, Epomops Gray, 1870, Hypsignathus H. Allen, 1861, Nanonycteris Matschie, 1899, and Plerotes Andersen, 1910. Beaufortia 39(4): 89-152.

Bergmans, W. 1997. Taxonomy and biogeography of African fruit bats (Mammalia, Megachiroptera). 5. The genera Lissonycteris Andersen, 1912, Myonycteris Matschie, 1899, and Megaloglossus Pagenstecher, 1885; general remarks and conclusions; annex: key to all species. Beaufortia 47(2): 11-90.
Bergmans, W., and F.G. Rozendaal. 1988. Notes on the collection of fruit bats from Sulawesi and some off-lying islands (Mammalia, Megachiroptera). Zoologische Verhandelingen 248: 1-74.

Bergmans, W., and P.J.H. van Bree. 1972. The taxonomy of the African bat Megaloglossus woermanni Pagenstecher, 1885 (Megachiroptera, Macroglossinae). Biologia Gabonica 3-4: 291-299.

Evans, H.E. 1993. Miller's anatomy of the $\operatorname{dog}, 3^{\text {rd }}$ ed. Philadelphia: W.B. Saunders.

Giannini, N.P., F.C. Almeida, N.B. Simmons, and R. DeSalle. 2006. Phylogenetic relationships of the enigmatic Harpy Fruit Bat, Harpyionycteris (Mammalia: Chiroptera: Pteropodidae). American Museum Novitates 3533: 1-12.

Giannini, N.P., and N.B. Simmons. 2003. A phylogeny of megachiropteran bats (Mammalia: Chiroptera: Pteropodidae) based on direct optimization analysis of one nuclear and four mitochondrial genes. Cladistics 19: 496-511.

Giannini, N.P., and N.B. Simmons. 2005. Conflict and congruence in a combined DNA-morphology analysis of megachiropteran bat relationships (Mammalia: Chiroptera: Pteropodidae). Cladistics 21: 411-437.

Giannini, N.P., J.R. Wible, and N.B. Simmons. 2006. On the cranial osteology of Chiroptera. I. Pteropus (Megachiroptera: Pteropodidae). Bulletin of the American Museum of Natural History 295: 1-134.

Handley, C.O., Jr. 1959. A revision of the American bats of the genera Euderma and Plecotus. Proceedings of the United States National Museum 110: 95-246.

Hayman, R.W. 1946. A new genus of fruit-bat and a new squirrel, from Celebes. The Annals and Magazine of Natural History, series 11, 12: 569-578.

Helgen, K.M. 2005. Systematics of the Pacific monkey-faced bats (Chiroptera: Pteropodidae), with a new species of Pteralopex and a new Fijian genus. Systematics and Biodiversity 3: $433-453$.

Juste, J., and C. Ibáñez. 1993. An asymmetric dental formula in a mammal, the São Thomé Island fruit bat Myonycteris brachycephala (Mammalia: Megachiroptera). Canadian Journal of Zoology 71: 221-224.

Kielan-Jaworowska, Z., R.L. Cifelli, and Z.-X. Luo. 2004. Mammals from the age of dinosaurs. Origins, evolution, and structure. New York: Columbia University Press.

Kock, D. 1969a. Eine neue Gattung und Art cynopteriner Flughunde von Mindanao, Phi- 
lippinen (Mammalia, Chiroptera). Senckenbergiana Biologica 50: 319-327.

Kock, D. 1969b. Eine bemerkenswerte neue Gattung und Art Flughunde von Luzon, Philippinen. Senckenbergiana Biologica 50: 329-338.

Koopman, K.F. 1994. Chiroptera systematics. Handbook of Zoology [vol. 8, part 60], Mammalia. New York: Walter de Gruyter.

Lawrence, B. 1939. Mammals. In T. Barbour, B. Lawrence and J.L. Peters (editors), Collections from the Philippine Islands, Bulletin of the Museum of Comparative Zoology at Harvard College 86(2): 28-73.

Leche, W. 1878. Zur Kenntniss des Milchgebisses und der Zahnhomologien bei Chiroptera. Acta Universitatis Lundensis: Lunds Universitets, Årsskrift 12: 1-37.

Marshall, C.R., E.C. Raff, and R.A. Raff. 1994. Dollo's law and the death and resurrection of genes. Proceedings of the National Academy of Sciences of the United States of America 91: 12283-12287.

Menzies, J.I. 1977. Fossil and subfossil bats from the mountains of New Guinea. Australian Journal of Zoology 25: 329-336.

Miles, A.E.W., and C. Grigson. 1990. Variations and diseases of the teeth of animals. Cambridge: Cambridge University Press.

Miller, G.S. 1907. The families and genera of bats. Bulletin of the United States National Museum 57: $1-282$
Phillips, C.J. 1971. The dentition of glossophagine bats: development, morphological characteristics, variation, pathology and evolution. Miscellaneous publication of the University of Kansas Museum of Natural History 54: 1-138.

Rui, A.M., and C.J. Drehmer. 2004. Anomalias e variações na fórmula dentária em morcegos de gênero Artibeus Leach (Chiroptera, Phyllostomidae). Revista Brasileira de Zoologia 21(3): 639-648.

Simmons, N.B. 2005. Order Chiroptera. In D.E. Wilson and D.M. Reeder (editors), Mammal species of the world: a taxonomic and geographic reference, 3rd ed. Baltimore: Johns Hopkins University Press, 312-529.

Slaughter, B.H. 1970. Evolutionary trends in chiropteran dentitions. In B.H. Slaughter and W.D. Walton (editors), About bats, Fondren Science Series 11: 51-83. Dallas: Southern Methodist University Press.

Thomas, O. 1908. The missing premolar of Chiroptera. The Annals and Magazine of Natural History, series 8, 1: 346-348.

Thonglongya, K. 1972. A new genus and species of fruit bat from South India (Chiroptera: Pteropodidae). Journal of the Bombay Natural History Society 69(1): 151-158.

Workman, M.S., L.J. Leamy, E.J. Routman, and J.M. Cheverud. 2002. Analysis of quantitative trait locus effects on the size and shape of mandibular molars in mice. Genetics 160: 1573-1586. 
Complete lists of all issues of the Novitates and the Bulletin are available at World Wide Web site http://library.amnh.org/pubs. Inquire about ordering printed copies via e-mail from scipubs@amnh.org or via standard mail from: American Museum of Natural History, Library-Scientific Publications, Central Park West at 79th St., New York, NY 10024. TEL: (212) 769-5545. FAX: (212) 769-5009. 